\title{
A Review of DNA Risk Alleles to Determine Epigenetic Repair of mRNA Expression to Prove Therapeutic Effectiveness in Reward Deficiency Syndrome (RDS): Embracing "Precision Behavioral Management"
}

Kenneth Blum, (iD) ${ }^{1-5}$ Bruce Steinberg, 6 Marjorie C Gondre-Lewis, ${ }^{7}$

David Baron,'

Edward J Modestino, (iD) ${ }^{6}$

Rajendra D Badgaiyan, (iD) $8-10$

B William Downs, " Debasis Bagchi," Raymond Brewer,

Thomas McLaughlin, (iD ${ }^{12}$

Abdalla Bowirrat, (iD) ${ }^{13}$

Mark Gold ${ }^{14}$

'Center for Psychiatry, Medicine \& Primary Care, Division of Addiction Research \& Education, Graduate College, Western University Health Sciences, Pomona, CA, USA; ${ }^{2}$ Eötvös Loránd University, Institute of Psychology, Budapest, Hungary; ${ }^{3}$ Department of Psychiatry, Wright State University Boonshoft School of Medicine and Dayton VA Medical Center, Dayton, OH (IE), USA; ${ }^{4}$ Department of Psychiatry, University of Vermont, Burlington, VT, USA; ${ }^{5}$ Division of Nutrigenomics, The Kenneth Blum Behavioral \& Neurogenetic Institute, Austin, TX, USA; ${ }^{6}$ Department of Psychology, Curry College, Milton, MA, USA; ${ }^{7}$ Developmental Neuropsychopharmacology Laboratory, Department of Anatomy, Howard University College of Medicine, Washington, DC USA; ${ }^{8}$ Department of Psychiatry, Icahn School of Medicine at Mount Sinai, New York, NY, USA; ${ }^{9}$ Department of Psychiatry, South Texas Veteran Health Care System, Audie L. Murphy Memorial VA Hospital, San Antonio, TX, USA; ${ }^{10}$ Long School of Medicine, University of Texas Medical Center, San Antonio, TX, USA; " 'Division of Nutrigenomics, Victory Nutrition International, Inc., Harleysville, PA, USA; ${ }^{2}$ Department of Psychopharmacology, Center for Psychiatric Medicine, Lawrence, MA, USA; ${ }^{13}$ Adelson School of Medicine \& Department of Molecular Biology, Ariel University, Ariel, Israel; ${ }^{14}$ Department of Psychiatry, Washington University, School of Medicine, St. Louis, MO, USA

Correspondence: Bruce Steinberg Department of Psychology, Curry

College, Milton, MA, USA

$\mathrm{Tel}+$ I 617-333-2226

Fax + $617-333-2316$

Email Bsteinbe4@gmail.com
Abstract: This is a review of research on "Precision Behavioral Management" of substance use disorder (SUD). America is experiencing a high prevalence of substance use disorder, primarily involving legal and illegal opioid use. A 3000\% increase in treatment for substance abuse has occurred between 2000 and 2016. Unfortunately, present day treatment of opioid abuse involves providing replacement therapy with powerful opioids to, at best, induce harm reduction, not prophylaxis. These interventions do not enhance gene expression and restore the balance of the brain reward system's neurotransmitters. We are proposing a generalized approach called "Precision Behavioral Management". This approach includes 1) using the Genetic Addiction Risk Severity (GARS, a 10 candidate polymorphic gene panel shown to predict ASI-alcohol and drug severity) to assess early pre-disposition to substance use disorder; 2) using a validated reward deficiency syndrome (RDS) questionnaire; 3) utilization of the Comprehensive Analysis of Reported Drugs (CARD ${ }^{\mathrm{TM}}$ ) to assess treatment compliance and abstinence from illicit drugs during treatment, and, importantly; 4) utilization of a "Pro-dopamine regulator (KB220)" (via IV or oral [KB220Z] delivery systems) to optimize gene expression, restore the balance of the Brain Reward Cascade's neurotransmitter systems and prevent relapse by induction of dopamine homeostasis, and; 5) utilization of targeted DNA polymorphic reward genes to direct mRNA genetic expression profiling during the treatment process. Incorporation of these events can be applied to not only the underconsidered African-American RDS community, but all victims of RDS, as a demonstration of a paradigm shift that uniquely provides a novel putative "standard of care" based on DNA guided precision nutrition therapy to induce "dopamine homeostasis" and rebalance neurotransmitters in the Brain Reward Cascade. We are also developing a Reward Deficiency Syndrome Diagnostic Criteria (RDSDC) to assist in potential tertiary treatment.

Keywords: substance use disorder, SUD, genomic disparity, dopamine, pro-dopamine regulation, KB220, GARS, homeostasis

\section{Introduction}

Success in survival is accompanied by the pleasure of reward satisfaction. In assessing the nature of the out-of-control epidemic of Substance Use Disorder (SUD) conventional perspectives portray SUD as occurring in people who are in some way impaired or somewhat broken, stigmatizing individuals. After more than 
six decades of published clinical research such diagnostic conclusions are most likely inaccurate. In our view, individuals who carry genetic predispositions to engage in excessive reward seeking or self-medicating behaviors, are arguably high-performing beings, most fit to survive. In a pristine environment with an abundance of healthy natural nutritional "fuel" resources (ie, high-performance fuel) such individuals would have better global/environmental awareness; be more focused, more competitive, better hunters, have greater athletic prowess, and/or be celebrities or leaders in their communities. But, in the absence of superior nutritional fuel resources, such individuals lack those attributes and are unable to achieve reward satisfaction from normal lifestyle thoughts and behaviors. Their inability to achieve reward satisfaction motivates their engagement in excessive reward-seeking or self-medicating behavior. An understanding of this duality in reward seeking behavior may eliminate the potential for a stigma. Our laboratory is focused on reducing stigma to for example alcoholism, by adaptation of the term "Hypodopaminism."

It is well known that America is experiencing an epidemic of Substance Use Disorder (SUD), associated with licit and illicit opiates/opioids used in the pursuit of reward satisfaction, to avoid pain, and to feel good. Between 2000 and 2016 drug treatment utilization has increased $3000 \%$. Unfortunately, present day treatment of opioid abuse involves providing replacement therapy with other powerful pharmaceutical opioids to, at best, induce harm reduction; but not as prophylaxis. These interventions do not nourish the ability to enhance gene expression and restore the balance of the brain reward system's neurotransmitters.

In 2013, the National Survey on Drug Abuse and Health $(\mathrm{NSDUH})^{1}$ estimated that 24.6 million people, 12 or older (9.4\% of the American population), used illegal drugs, in the past month and this number increased further to 35.8 million (13\% of the population) in 2019. During this six-year time frame, 11.2 million additional people endorsed using illicit drugs during the prior month and 7 million additional people initiated use of marijuana (cannabis). In addition, illicit, pastyear drug use for individuals $12+$ years, increased from 41.6 million to 57.2 million people. In 2019, the three most often used illicit drugs, were marijuana, opioids and pain relievers. ${ }^{2}$

The 2014 and 2019 data from NSDUH indicate slight declines in the percentages of past year users of heroin and users of pain reducing medications, with Opioid Use Disorder also decreasing in that time frame. However, the prevalence of past year opiate use, for people twelve years and older, was still high in 2019 at 10.1 million individuals. Among those individuals, $92 \%$ of them misused pain relievers, exclusively. ${ }^{2}$

The number of new drug users in 2013 was 2.8 million. New users increased to 16.5 million in 2019 , with another 4.9 million new users of alcohol, followed by marijuana with 3.5 million new users. ${ }^{2}$ The cost of alcohol abuse is high. Alcohol was associated with 97,000 reports of date rape and sexual assault, and 696,000 physical assaults, in general, were committed by students affected by alcohol. ${ }^{3}$

The National Institute of Drug Abuse (NIDA) recently presented their Monitoring the Future (MTF) Survey ${ }^{4}$ of drug use and attitudes for 42,500 8th, 10th and 12th graders from almost 400 public and private schools in the US. The MTF Survey found that vaping is prevalent and has increased for high school students and Marijuana use has increased from 2018 to 2019. Lifetime use of alcohol has continued to decline from 1994 through 2019 for all high school grades. Misuse of narcotics "other than heroin" has declined for 12 grade students. Vicodin use has decreased for 10th and 12th graders and Oxycontin use has also decreased for 12th grade students. Misuse of prescription opioids is low, and heroin use has declined from 2014 to 2019 for 10th and 12th grade students.

While this general landscape seems promising the opioid crisis is indeed, during this period of a viral pandemic, increasing. Most recently the Director of the National Institute of Drug Abuse (NIDA), Nora Volkow commented that job losses and social isolation associated with the Covid-19 pandemic may increase opioid overdoses by $30 \%$ to $40 \% .^{5}$ Although this statistic is anecdotal, it is indeed a grave concern to healthcare professionals. The cost of the opioid epidemic is high. The Society of Actuaries ${ }^{6}$ reported that the United States had experienced 400,000 opioid-related deaths from 1997 to 2017 and estimated the total economic burden of opioid misuse and death, from 2015 to 2018 to be 631 billion dollars. Their 2019 cost projection was 188 billion dollars. These figures include the costs of additional health-care services, premature mortality, child and family support, lost productivity, education and criminal justice activity.

\section{Perspective and Goals of This Review}

Understanding these facts, one aim of this review is to delineate the current genomic disparity of various ethnic groups, especially African-Americans, and discuss how 
variations in dopamine (DRD2) receptor alleles (A1 vs A2) may convey vulnerability for Reward Deficiency Syndrome (RDS). RDS is a cluster of disorders, including drug and alcohol addiction that are related to low dopamine metabolism. We must note that in discussing genomic and racial disparity, we are not implying that race or ethnicity causes RDS conditions, but explicitly indicating that variants in dopamine D2 alleles, moderated by the social and economic conditions of our lives, may increase our risk for RDS illnesses such as alcoholism and Opiate/ Opioid Use Disorder (OUD). The investigation of genetic variants related to addiction, for example, in the AfricanAmerican community is important since AfricanAmericans have been under represented in research on genetic correlates of addiction. ${ }^{7}$

It is indeed important not to target any particular group whether Caucasian, Latino, Black or Asian, but to encourage more genomic type research to at least include an array of these diverse ethnicities in their respective studies before any unfounded interpretations are enunciated.

In addition, another goal of this review is to provide some novel concepts that could become future treatments and a prophylactic model for the entire field of Reward Deficiency Syndrome (RDS). RDS is the umbrella term for all non-substance and substance-dependent behaviors, coined by one of our authors (KB) in 1995. The treatment and prophylactic model we will discuss includes assessment of genetic vulnerability for RDS, use of an RDS questionnaire, monitoring compliance with drug treatment, use of pro-dopamine regulation to establish dopamine homeostasis and impact DNA polymorphic reward genes to influence mRNA genetic expression during drug treatment. These innovations could have significant value for minority populations and people of color who have been dramatically under-served by the health-care system and have had limited access to innovative health care and substance use treatments.

\section{Substance Use Disorder and Ethnicity}

Wu et $\mathrm{al}^{8}$ employed a case-control design to study the association of the A1 and B1 DRD2 alleles with smoking vs nonsmoking status in lung cancer cases and controls for their African-American and Mexican-American participants. They found that $50 \%$ of a community-based sample of 111 AfricanAmerican controls (albeit not properly screened to eliminate all RDS behaviors) carried the DRD2 A1/A2 receptor alleles, compared to $56 \%$ for Mexican-American control participants. This difference was not statistically significant. These alleles, in combination with other genetic variants that affect the Brain Reward Cascade, have been postulated by Blum et $\mathrm{al}^{9-11}$ to contribute unhealthy reward seeking behaviors consistent with how the DRD2 A1 allele functions in reward regardless of race or ethnicity. Combined with the important role of social, economic and legal variables, the net potential effect of an individual's genetic and epigenetic landscape on behavior can have a devastating inequitable outcome on the life of that individual and on their community. In speaking of genetics and behavior, we are not implying genetic determinism, but rather a genetic contribution to a complex interaction of factors that shape the final behavioral and societal outcome also involving epigenetic insults. Indeed, African-American communities are over policed and experience drug possession charges substantially more frequently than Caucasian drug users. ${ }^{12}$ Furthermore, compared to Caucasian drug users, addiction in the AfricanAmerican community is often criminalized, ${ }^{13}$ rather than treated as a medical emergency.

The NSDUH 2020 survey $^{2}$ revealed that 2019 rates of illicit, past month drug use for adults, $18+$ were $14 \%$ for Whites, $15.3 \%$ for Blacks or African-Americans, $14.8 \%$ for Native Americans/Alaskan Natives, 11\% for Native Hawaiians or Pacific Islanders, 5.9\% for Asians, and $11.3 \%$ for Hispanic or Latino individuals. Rates of SUD for adults were $8.1 \%$ Whites, $7.6 \%$ for Black or AfricanAmericans, 7.0\% for Hispanic or Latinos, 4.6\% for AsianAmericans, $10.2 \%$ for Native American or Alaskan Natives and $8.3 \%$ for Native Hawaiian or Pacific Islanders. Although SUD rates were somewhat higher for Native Americans/Alaskan Natives and Native Hawaiian or Pacific Islanders, and lower for Asians, it is important to note that SUD rates for White, Black, and Hispanic or Latino individuals are fundamentally the same.

In summary, the above statistics do not support big differences between ethnic groups for Substance Use Disorder (SUD), which, in our view, may be more related to an interaction between genetic vulnerability for addiction, epigenetic factors and the social and economic conditions that affect peoples' lives, rather than general ethnic values and attitudes. We believe that the data we have presented suggest that the allegations of racial profiling, associated with the war on drugs, are likely correct; only the causes espoused by conventional perspectives are to be disputed. The take home message here is that racial or ethnic bias in the investigation and prosecution of drugrelated crimes cannot be justified and should cease. 
While there may not be a difference in a "cultural romance with drugs" in terms of comparative ethnic groups (ie, African-Americans vs American Caucasians), genomic disparity is an important issue that can inform targeted, personalized therapeutic strategies to treat drug addiction. Both treatment and prevention tactics must be adequately addressed, and informed by a psychosocial genetics approach. In an effort to shed some new light on this very important issue, the authors, have gathered information from an array of different backgrounds, pooling experience, academic knowledge, and data, that indicates a paradigm shift called "Precision Behavioral Management" is occurring and has therapeutic potential in the future. ${ }^{14-20}$

\section{Precision Behavioral Management}

While we are particularly interested in the reasons for addiction to drugs within the African-American and other ethnic groups in various communities across America, we are proposing a generalized approach called "Precision Behavioral Management" to address this problem. This approach consists of; 1) Using the Genetic Addiction Risk Severity assessment (GARS, a 10 candidate polymorphic gene panel shown to predict the Addiction Severity Index, ASI-alcohol and drug severity $)^{21}$ to assess early pre-disposition to Substance Use Disorder;, ${ }^{9,22}$ 2) A validated RDS questionnaire, ${ }^{23} 3$ ) Utilization of the Comprehensive Analysis of Reported Drugs $\left(\mathrm{CARD}^{\mathrm{TM}}\right)^{9,22}$ to assess treatment compliance and abstinence from illicit drugs during treatment ${ }^{24,25}$ and, importantly; 4) Initiation of oral and IV therapy utilization of a DNA guided "Pro-dopamine regulator (KB220Z and KB220 respectively)" to optimize gene expression, restore the balance of the Brain Reward Cascade's neurotransmitter systems and prevent relapse by induction of dopamine homeostasis ${ }^{26,27}$ and; 5) Utilization of targeted DNA polymorphic reward genes to direct mRNA genetic expression profiling during the treatment process. ${ }^{28}$ These concepts will provide a framework for this review. Incorporation of these events can be applied in benefit of, for example, the African-American community, as a demonstration of a paradigm shift that has been the subject of an NIH grant. This unique program is called the "Reward Deficiency Syndrome Solution System"TM (RDSSS).

The following sections of this review will provide the rationale for our proposition of "Precision Behavioral Management". Blum's group is currently engaged in the novel development of utilizable Reward Deficiency
Syndrome diagnostic criteria which will be published elsewhere.

\section{Genetic Addiction Risk Severity (GARS)}

The Brain Reward Cascade (BRC) describes the genetic and neurotransmitter interactions that regulate the release of dopamine. Alterations in the BRC, whether due to genetic or epigenetic factors, may predispose individuals to altered pain tolerance and addictive behaviors. The GARS accurately predicts RDS component behaviors, including vulnerability to pain, addiction and other compulsive behaviors. In this review, the authors propose innovative strategies for fighting opioid and prescription drug abuse and death, based on the role of dopaminergic tone in pain pathways. The mesolimbic projection system may influence pain sensitivity, and genetic polymorphisms associate with a predisposition to pain vulnerability or tolerance. Genetic polymorphisms offer targets for therapy that could help in pain treatment and, most important, identify risk for subsequent addiction.

The evaluation of genes like CB1, mu receptors and PENK, with pharmacogenomic tests offers the possibility to provide pharmacogenomic, individualized solutions, improve gene expression, rebalance neurotransmitters in the BRC to optimize mental and physical performance and improve treatment results. The genetic identification of RDS behavior risks, especially in groups with an increased percentage of genetic vulnerabilities, may be an important early technique to assist government agencies in improving the distribution of available financial resources. ${ }^{29,30}$

Blum et al was the first group to report a genetic association with severe alcoholism ${ }^{10}$ and later, cocaine. ${ }^{11}$ Although there was disagreement within the scientific community in the 1990s, the Dopamine D2 receptor (DRD2) gene, located on chromosome $11 \mathrm{q} 22 \mathrm{q} 23,{ }^{31}$ was the first gene identified to be associated with not only severe alcoholism, but more importantly, non-specific dopaminergic reward system impairment/ inadequacies (anhedonia), which are central to all addictive behaviors. ${ }^{32}$ Following an historic controversy, Goldman's group reported a meta-analysis of 62 studies of DRD2 and more than 16,000 participants with Alcohol Use Disorder (AUD). Alcohol Use Disorder showed a significant association with the rs1800497 Single Nucleotide Polymorphism (SNP). According to Goldman's group ${ }^{30}$ the association resulted from low allele frequency in controls in positive studies which also explained some of the differences between these experiments. This is exactly what one should expect. The lower allelic presence of the DRD2 A1 allele in controls will improve 
robustness of association, especially when the rs1800497 SNP is found in approximately one-third of the American population. This was discussed by Blum's and Goldman's laboratories over 30 years ago ${ }^{33}$ and indicates the need for more robust controls that have been seriously screened to eliminate all RDS behaviors. We suggested that future gene research producing positive associations with dopaminergic polymorphisms and RDS behaviors, using controls that eliminated addictive, compulsive and impulsive behaviors in participants and their families could have important implications in any diverse population. ${ }^{34}$ Recruitment of these 'super controls' can prove challenging given the number of behaviors and psychiatric conditions under the umbrella of RDS or that are comorbid with an RDS condition.

One source of differences in this research is variation in the frequency of A1 alleles in the control groups. Barr and Kidd ${ }^{35}$ studied the frequencies of the DRD2 A1 allele in various populations. They examined 381 unrelated people from 16 different populations. The frequency of the A1 allele varied from 0.09 in Ashkenazi Jews to 0.75 in Native American Indians. Due to these important variations in A1 allele frequency, as association study of this polymorphism must control for the ethnicity of the participants. The results of such studies must be interpreted with caution, which suggests a requirement to highly screen all RDS behaviors in controls (super controls). In fact, utilization of an approach to reduce hidden RDS behaviors in controls of families by Hill et $\mathrm{al}^{36}$ showed a rather low frequency of the DRD2 A1 allele, and this finding helped identify the linkage to severe alcoholism. Specifically, indicators of more severe alcoholism, eg, symptoms of physical dependence, earlier age of onset, or comorbid antisocial personality disorder, supported evidence for linkage. In addition, the Feighner criteria for alcoholism combined with one or more symptoms of physical dependence gave some evidence of linkage between two dopamine receptor alleles (Taq1 A and D4). Early age of onset and physical dependence (morning drinking, inability to stop drinking, withdrawal symptoms, binging) also gave some evidence for linkage. Finally, alcoholics with personality disorder showed significant differences in allele composition compared to nonalcoholics, for both D2 polymorphisms. ${ }^{37}$

It is indeed important to consider protective genetic mechanisms as a way of potential interventional therapeutic targets. Blum et $\mathrm{al}^{38}$ proposed that the Taq1 A2 allele of the dopamine D2 receptor gene is associated with a subtype of schizophrenia, not vulnerable to SUD, and the Taq1 A2 allele may provide some protection against alcohol addiction or dependence on other drugs of abuse. ${ }^{39}$ Previous research suggests that a deficiency of gamma type endorphins, that has been associated with schizophrenic type psychosis, may be a mechanism that explains alcohol seeking in schizophrenics with SUD. ${ }^{40}$ The present authors also suggest that schizophrenics who seek alcohol may be self-medicating by decreasing abnormal dopaminergic activity in the nucleus accumbens (NAc) via increased gamma endorphin activity. Further support of shared genetics is also derived from the Psychological Genetics of Addiction (PGA) ${ }^{23}$ studies in Hungary which suggest a substantial co-occurrence of addictions and compulsive behaviors. The authors emphasize the importance of studying the common neural, genetic and psychological mechanisms that may underlie this association. The PGA studies also support the component model of addictions and the RDS concept that suggests different addictive and compulsive behaviors share a common etiological and phenomenological background. ${ }^{41}$

Genes and the pathways underlying addiction have been revealed by new research technologies. $\mathrm{Li}$ et $\mathrm{al}^{42}$ in a comprehensive analysis of peer reviewed studies between 1976 and 2006, integrated 2343 pieces of evidence that linked chromosome regions and genes to addiction by single gene strategies, microarray, proteomics or genetic studies. Fifteen hundred human addiction related genes were identified. Their findings produced the Knowledgebase for Addiction Related Genes (KARG) network map (https://open data.pku.edu.cn/dataset.xhtml?persistentId=doi:10.18170/ DVN/OZUJRU), a user friendly molecular database of genes related to addiction.

Their meta-analysis extracted 396 genes and each gene was supported by at least two lines of evidence. Li et $\mathrm{al}^{42}$ identified 18 statistically significant molecular pathways. Five of the pathways "enriched for all four different types of addictive drugs" including the Gonadotropin-releasing hormone (GnRH) signaling pathway and the gap junction, were suggested as underlying the rewarding and addictive effects of drugs. These pathways were integrated into a hypothetical molecular network for addiction. The network included both fast and slow positive feedback loops that were interconnected with calcium/calmodulin-dependent protein kinase II (CAMKII), a protein kinase that is involved in memory, which may explain the relative permanence of addiction. Finally, the common elements in this research include dopaminergic and glutaminergic genes.

The treatment of patients would be enhanced by classifying them for genetic risk for alcohol and drug seeking behavior, prior to the initiation of residential or non-residential chemical dependency or pain treatment programs. The authors have 
developed an addiction risk severity index based on 11 polymorphisms in 10 genes that contribute to the operation of the brain's reward system. The Genetic Addiction Risk Severity test (GARS) includes six Single Nucleotide Polymorphisms (SNPs) in the DRD1, DRD2, DRD4, COMT, and OPRM1 genes. The GARS test also includes four simple sequence repeats (SSRs) in the DAT1, DRD4, MAOA and 5HTT transporter genes, as well as a dinucleotide polymorphism in the GABRA3 gene. Blum's group ${ }^{22}$ approached the genetic risk for alcohol and substance abuse by examining the potential contribution of reward genes to a hypodopaminergia, and its linkage to RDS related substance abuse risk. The Blum et $\mathrm{al}^{21}$ report of findings included 393 poly drug using patients selected from eight independent treatment centers around the United States. The severity of substance misuse was evaluated with the Addiction Severity Index (ASI-MV). Saliva samples were provided by 273 patients, who also had ASI phenotyping, and these samples were subjected to DNA genotyping. The average age of individuals in the study was 35.3 years (S.D. 13.1 years, range was $18-70$ years). The sample was $57.8 \%$ male $(n=160)$ and $88.1 \%(n=244)$ white (self-report of race). The average number of GARS alleles was 7.97 (S.D. $=2.34$ ), and the number of alleles ranged from 3 to 15 . The genotypes were all in Hardy-Weinberg equilibrium (HWE). Initial evaluation of the association between the GARS results and the ASI scores, using Fisher's Exact Test, showed a significant predictive value $\left(\mathrm{x}^{2}=8.84, \mathrm{df}=1, \mathrm{p} .004,2\right.$ tailed $)$. This finding was still statistically significant after controlling for age $(\mathrm{p}<$ $0.01)$. Chi-square $(\mathrm{p}<0.05)$ and linear regression $(\mathrm{b}=-0.122$, $\mathrm{t}=-1.91, \mathrm{p}=0.057,2$ tailed) analyses of the relationship between the GARS panel and the ASI drug severity risk score were also significant, though less robust than the Fisher Exact Test result. The association between the GARS panel and the ASI score was statistically significant at $p=0.028$, following correction for our a priori hypothesis. The Blum et al method data is the first report of the development of the GARS measure of alcohol and drug severity risk. ${ }^{21}$

Although it is important to conduct research with RDS free controls, studies to date have not accomplished this. Case-control studies, however, have used participants free of SUDs. We contend that the use of RDS free controls, if adopted properly, would decrease the frequency of false results and confusion regarding the contribution of genetics to addiction. ${ }^{21}$ Given the previous literature we have cited, we believe that there is a strong association between alcohol and drug risk. In our report, ${ }^{21}$ we note a total of 110,241 cases and 122,525 controls that came from the current literature. Although we can differ over the criteria for selecting these controls (eg, blood donors), there are many case-control studies reporting selective association of these risk alleles (measured with GARS), generally indicating the presence of hypodopaminergia in both cases and controls, thus providing genetic confusion, attenuated robustness and potentially spurious results.

In fact, the Blum et al study ${ }^{21}$ found that $\geq 7$ risk alleles load onto prediction of alcohol severity, whereas $\geq 4$ risk alleles load onto prediction of drug severity. The risk for alcohol and drug use severity increase, with increasing numbers of sequence variations in the genes that regulate dopamine signaling. Age is a meaningful covariate for the alcohol severity scores. Global research provides evidence that DRD2 receptor numbers decline with advancing age. ${ }^{43-46}$ Additional research may be needed to verify the contribution of these and other genetic variations to SUD. Even though there is some disagreement regarding the candidate approach compared to micro-array or cluster analysis techniques, ${ }^{47-54}$ the GARS assessment offers valuable information for substance use treatment, screening of patients for pain treatment and relapse prevention. ${ }^{21}$

\section{Reward Deficiency Syndrome (RDS) Questionnaire}

In conjunction with Zsolt Demetrovics in the Eötvös Loránd University, Institute of Psychology, Budapest, Hungary, an unpublished 29-item RDS questionnaire, was reduced from an initial 51 items that was generated based on the RDS construct. The questionnaire has been validated in over 1726 individuals attending college. Demetrovics and associates utilized Exploratory and Confirmatory Factor Analyses on four independent subsamples of the 1726 subjects. Specifically, a 5-factor solution had an optimal goodness of fit with a final factor analysis result: a reward deficiency trait was the main factor (Z. Demetrovics, personal communication, 2016).

This work will be published elsewhere with further indepth details.

The Reward Deficiency Factor showed correlations with gender, sensation seeking and impulsivity. The reward deficiency trait showed greater expression in females. In addition, the reward deficiency trait was predicted by higher levels of sensation seeking and impulsivity. Impulsivity positively predicted the need for being in action. Male subjects showed a higher level of need for action. Need for overstimulation was not associated with any predictors. Finally, risk seeking behavior was 
positively associated with sensation seeking and impulsivity while reward deficiency was under control. ${ }^{55}$ We are aware that when evaluating RDS in AfricanAmericans or other cultures and geographies that differ from the Hungarian group, a culturally appropriate RDS questionnaire needs to be developed and validated for the RDS component to be informative.

\section{Comprehensive Analysis of Reported Drugs (CARD)}

In response to the rampant substance use problem in America, the Comprehensive Analysis of Reported Drugs (CARD) is providing treatment centers an objective means of evaluating their clients' compliance with prescribed treatment and abstinence from illicit drugs. For many decades, Dominion Diagnostics has supplied modern, advanced drug testing education and support to drug treatment clinics. Dominion was unique in helping clinics to monitor drug elimination over time, using CreatinineAdjusted levels. In 2004, the company was repeatedly asked to add medication compliance to their summary reports. In collaboration with the clinics, the following sources of data were developed: 1) a summary of testing results, including the number of patients who tested positive for illicit drugs in the prior quarter; 2) the number of patients receiving prescriptions for treatment related drugs in the quarter; 3 ) the number of patients taking the medication drugs; 4) identification of illicit drugs used by the patients; and 5) honesty of the patients in their self-reports of drug use. Following many iterations, the CARD assessment project was rolled out as a beta test in 2009. Notably, in 2011 Dominion began reviewing the data summaries followed by Blum et $\mathrm{al}^{25}$ data analysis in 2012. A multistate sample of 2919 individuals, drawn from in-patient and outpatient settings, was retrospectively studied for treatment compliance (presence of prescribed medications) and abstinence (absence of prohibited drugs) verified by urine testing. The data from initial and final urine tests revealed a $67.2 \%$ compliance rate and a $39.2 \%$ abstinence rate. During a one year follow-up period, a randomly selected subset of 511 individuals was studied longitudinally with repeated urine tests to assess compliance and abstinence. Statistically significant increases in abstinence $(\mathrm{p}<0.001)$ and compliance $(\mathrm{p}<0.001)$ over time were observed. Increased compliance and abstinence, over time, may be attributed to the frequent use of urine testing and the beneficial effect of CARD on patient management and communication. ${ }^{25}$ In addition, Buprenorphine/Naloxone patients, involved in Opioid Substitution Programs, demonstrated statistically significant, increased compliance and abstinence during a one year, follow-up period. $^{24,56}$ These encouraging initial findings suggest that CARD is useful for clinicians in establishing the presence or absence of illicit drugs in their clients. Additional research is necessary to establish long-term treatment benefits. CARD continues to be upgraded and there is now an inclusion of an expanded mental health panel of medications (ie, anti-depressants, etc.).

\section{Pro-Dopamine Regulator (KB220 and Variants)}

The dopaminergic-glutaminergic optimization complex, KB220, KB220Z and its variants were designed to balance the brain's reward system through induction of "dopamine homeostasis". These preparations offer potential clinical benefits to individuals suffering from RDS and they may support their recovery from dependence on opiates/opioids and other addictive behaviors. ${ }^{57-59}$ What follows is a review of biochemical actions of commonly used pharmaceutical Medication Assisted Treatment (MAT) and their potential anti-reward activity, a justification for the use of KB220Z, and an explanation of how the KB220Z is purported to target the dopamine pathway to enhance reward. Dopamine, serotonin, endorphins, cannabinoids and glutamine are important elements in the operation of the brain's reward system. The United States is in the grip of an extraordinary level of opiate/opioid use, with 127 deaths per day, according to the Centers for Disease Control (CDC).

Unfortunately, cases of heroin overdose are increasing. Although MAT has been approved by the FDA, for nicotine, opiate and alcohol dependence, MAT is not yet available for abuse of stimulants or cannabis (Table 1). Acute use of MAT is beneficial in supporting "psychological extinction", however, its chronic use blocks dopaminergic function, and dopamine is essential for the experience of pleasure and satisfaction through normal life experiences. Both the National Institutes on Alcohol Abuse \& Alcoholism (NIAAA) and the National Institute on Drug Abuse (NIDA), institutions that deal with drug dependence and alcoholism, recognize the problem with MATs and support research into improved treatments.

The development of SUD treatments that affect dopamine and the brain reward system is an ongoing challenge. 
Table I United States Federal Drug Authority (FDA) Approved Pharmaceutical Agents

\begin{tabular}{|c|c|c|c|}
\hline Drug & Company & Purpose & $\begin{array}{l}\text { Approval } \\
\text { Date }\end{array}$ \\
\hline Zubsolv $^{\circledR}$. Zubsolv ${ }^{\circledR}$ (buprenorphine and naloxone) & Orexo $A B$ & Treatment of opioid dependence & July 2013 \\
\hline Vivitrol $^{\circledR}$ extended release naltrexone & Alkermes & Prevention of relapse to opioid dependence & October 2010 \\
\hline Vivitrol $^{\circledR}$ Naltrexone & Alkermes & Treatment of alcohol dependence & April 2006 \\
\hline CHANTIX $^{\circledR}$ (varenicline) & Pfizer & Treatment of nicotine addiction & May 2006 \\
\hline Acamprosate calcium & Campral & Treatment of alcoholism & 2004 \\
\hline $\begin{array}{l}\text { Suboxone }{ }^{\circledR} \text { (buprenorphine/naloxone) Subutex }{ }^{\circledR} \\
\text { (buprenorphine) }\end{array}$ & Reckitt Benckiser & Treatment of opiate dependence & October 2002 \\
\hline Nicoderm CQ ${ }^{\circledR}$ Nicorette ${ }^{\circledR}$ & GlaxoSmithKline & For smoking cessation & May 1997 \\
\hline Naltrexone Hydrochloride oral tablets & Dupont & $\begin{array}{l}\text { Tablet form ( } 50 \mathrm{mg} \text { taken daily) for the treatment } \\
\text { of alcoholism }\end{array}$ & 1994 \\
\hline Antabuse $^{\circledR}$ (disulfiram) & $\begin{array}{l}\text { Odyssey } \\
\text { Pharmaceuticals }\end{array}$ & Treatment of alcohol dependence & 1951 \\
\hline
\end{tabular}

Notes: Febo M, Blum K, Badgaiyan RD, Perez PD, Colon-Perez LM, Thanos PK, et al. Enhanced functional connectivity and volume between cognitive and reward centers of naïve rodent brain produced by pro-dopaminergic agent KB220Z. PLoS ONE. 2017; 12(4): e0174774. @ 2017 Febo et al. This is an open access article distributed under the terms of the Creative Commons Attribution License. ${ }^{109}$

Table 1 presents, MAT approved by the FDA, to combat substance abuse. Although these approaches have been helpful to some patients, they do not prevent cravings and relapse. Recent results from the CARD study ${ }^{25}$ of abstinence from drug use and compliance with MAT in inpatient and outpatient settings revealed that only $39 \%$ of patients maintained abstinence but in fact $67 \%$ were compliant during the period of the research. However, the data indicated a trend towards increasing abstinence and compliance over a one year follow-up period. ${ }^{24,25}$ The authors acknowledged that these preliminary results require further research. The agents approved by the FDA for MAT may either reduce craving or block the pleasurable effect of drugs. Unfortunately, the latter effect may prevent patients from experiencing normal satisfaction from everyday life experiences. An overall analysis of CARD data for patients on MAT with combined buprenorphine and naloxone treatment (bup/nal) revealed that more than $92 \%$ of patients had evidence of bup/nal over the one year followup period, indicating good compliance. However, $47 \%$ of these patients also gave evidence of concomitant illicit drugs in their urine samples. Compliant patients, however, were more likely to be abstinent during treatment than non-compliant patients. $^{24}$

A review of the existing FDA-approved drugs to treat various types of SUD behaviors reveals that the opposite or anti-reward mechanisms seem to predominate the listing (Table 1). Briefly, it is well known that narcotic antagonists (in any form) attenuate euphoria via opioid receptor blockade. ${ }^{60,61}$ Buprenorphine/naloxone may not consistently affect the cingulate gyrus or prevent relapse, and when used chronically, may have significant antireward characteristics that include a flat emotional affect due to lack of dopamine homeostasis. ${ }^{62}$ Bupropion may block DA re-uptake but does not increase extracellular DA in man. ${ }^{63}$ Acamprosate calcium regulates chemically induced release of dopamine in the Nucleus Accumbens (NAc) ${ }^{64}$ Decreased activation of the DA system and the failure to release adequate mesolimbic DA in the Nucleus Accumbens (NAc) over time can produce depression and potential suicidal ideation. While this is a bold statement, N-methyl-D-aspartate (NMDA) antagonists are known to inhibit glutamatergic drive in the Ventral Tegmental Area (VTA) ultimately resulting in decreased dopamine release at the NAc. ${ }^{65}$ There are studies showing poor outcomes with Acamprosate calcium in daily drinkers. ${ }^{66}$

Individuals with RDS have a hypodopaminergic state or trait. Properties of a hypodopaminergic trait might include having reduced receptors for serotonin and/or dopamine, or a rapid rate of synaptic dopamine breakdown due to a high catabolic genotype of the COMT gene. ${ }^{67}$ A hypodopaminergic state can be the result of the toxic 
effects of drugs like alcohol or even stress. ${ }^{68,69}$ The hypodopaminergic state or trait predisposes individuals to behave or medicate themselves in ways that stimulate dopamine release. Methods may include the use of cannabis, stimulants, opiates, alcohol, gambling, sex, nicotine, and even extreme internet gaming activities. Imaging studies $^{70,71}$ document that individuals who abuse drugs have marked reductions in dopamine receptors and dopamine release and decreased dopamine activity is associated with increased impulsivity. ${ }^{72}$ The reduction in DA activity is correlated with reduced activity in several brain regions important for the regulation of behavior. The orbitofrontal cortex, a region of the brain that is involved in salience attribution, demonstrates decreased activity which results in compulsive behaviors. The cingulate gyrus, which is involved in inhibitory control, also shows decreased activity. Reduced cingulate activation contributes to impulsivity. Finally, the dorsolateral prefrontal cortex, which is involved in executive function, is disrupted which results in impaired regulation of intentional actions. ${ }^{70}$

Current treatment approaches to psychoactive substance abuse have not been very successful which provides an opportunity for new approaches to this problem. Chronic in vivo research with a D2 receptor agonist produces down-regulation, ${ }^{73}$ which is consistent with chronic treatment with an established D2 agonist, Quinpirole. ${ }^{74}$ In contrast, in vitro studies demonstrated that regardless of genetic antecedents, acute stimulation with Bromocriptine, a known $\mathrm{D}_{2}$ agonist, produces a notable increase in $\mathrm{D}_{2}$ receptors within the DA system. ${ }^{75-81}$ Stimulation of D2/ D3 receptors signal negative-feedback-mechanisms that induce mRNA expression ${ }^{82}$ in the mesolimbic system and cause a proliferation of $\mathrm{D} 2$ receptors that results in significant clinical benefits for alcoholics. ${ }^{83}$ These results support the proposition that excessive craving behavior may be due to reduced numbers of DRD2 receptors. In contrast, drug cravings and the likelihood of relapse may be decreased by a normal or adequate number of D2 receptors. Thus, a treatment goal to prevent relapse of substance abuse might be the induction of increased (but balanced) D2 receptors in genetically vulnerable individuals. ${ }^{70}$ In addition, humans with alcohol use disorder have demonstrated reduced DRD2 receptor ligand binding in the striatum. ${ }^{84,85}$ Feltman et $\mathrm{al}^{86}$ have noted that chronic alcohol use might be an expression of reduced levels of D2 receptors, resulting from a reduction in DRD2-DRD2 homoreceptor complexes and gene expression. In addition, these authors suggest that given the antagonistic relationship between the adenosine A2A receptor (A2AR) and DRD2 receptors, reduced affinity and signaling of the DRD2 receptor population might result from the increased density of A2AR-DRD2 heteroceptor complexes. Thus, in humans with Alcohol Use Disorder (AUD), decreased levels of striatal DRD2 and decreased protomer affinity in the striatal A2AR-D2R heteroceptor complex offers a promising target of treatment for AUD.

Prior theories about dopamine and SUD as well as current animal models of drug dependence suggest that normalizing dopamine activity in the brain's reward system is a productive approach to treatment. ${ }^{87}$ Compounds that selectively act on DA receptors affect long lasting cellular and intracellular adaptations, like desensitization and super sensitivity, causing therapeutic agents to fail to normalize dopamine at the level of neural circuitry. ${ }^{88}$ The challenge is to use "gentle" DA agonist therapy to activate D2 receptors in the mesolimbic pathway. The nutraceutical $\mathrm{KB} 220 \mathrm{Z}$ was developed to accomplish this task in the brain reward cascade. ${ }^{89}$ The idea that KB220, and its enhanced variant KB220Z, possibly regulate DA is best described in an annotated bibliography that lists the studies showing the clinical effects of KB220Z. ${ }^{90}$ Please note that several project names/codes have been used over the years for the KB220Z formula such as SG8839, LG839, SAAVE, Synaptamine, PCAL-I03, and KB220.

The following information provides evidence of the clinical benefit of $\mathrm{KB} 220 \mathrm{Z}$, without addressing the issue of the neural mechanisms involved in achieving dopamine homeostasis. KB220 variants are formulations of a nutraceutical complex that have been studied extensively in both animals and humans. A detailed review article, ${ }^{90}$ as well as other articles, ${ }^{17,91-104}$ provide information on preclinical and human trials. The supplement (Table S1) provides references for research directed with KB220Z variants. In summary, Gondré-Lewis' group showed that KB220Z, when administered to genetically alcoholpreferring $(\mathrm{P})$ rats, significantly attenuated ethanol consumption and operant-responding for $10 \%$ ethanol. Behavioral traits that mimic human neuropsychiatric conditions, including risk-taking behavior and hyperactivity were also attenuated in P rats. Although effective when delivered subcutaneously, intraperitoneally, and orally, this work showed that KB220 can act faster depending on route of administration ${ }^{105}$ The supplement (Table S1) provides data supporting the role of $\mathrm{KB} 220 \mathrm{Z}$ in reducing symptoms of drug and alcohol withdrawal in humans. 
Patients in recovery experienced reduced stress, measured by skin conductance level (SCL), and they demonstrated improved behavioral, emotional, social and spiritual wellbeing (BESS scores). Following detoxification, patients using KB220Z, compared to placebo, showed a six-fold reduction in leaving treatment against medical advice. After one month of treatment with KB220Z, healthy participants showed increased concentration. They also showed a decreased craving for nicotine, cocaine, heroin and alcohol (for an update of these studies see reference. $^{90}$ )

A few clinical benefits of KB220Z merit highlighting. Reduction in inappropriate sexual behavior has also been demonstrated. ${ }^{96}$ In addition, use of $\mathrm{KB} 220 \mathrm{Z}$ has reduced the frequency of lucid nightmares, a symptom of Posttraumatic Stress Disorder (PTSD) in patients with PTSD. ${ }^{97}$ Human studies with quantitative electroencephalography (qEEG) revealed that KB220Z moderated theta frequencies in the anterior cingulate cortex. ${ }^{98}$ An fMRI pilot study of 5 substance dependent individuals, abstinent from heroin, showed that a single dose of KB220Z, compared to placebo, produced improvement in a prefrontal-cerebellar-occipital neural network, and increased activation of the NAc. ${ }^{99}$ Also, known obese patients, who were carriers of the $\mathrm{D}_{2}$ receptor $\mathrm{A} 1$ allele, had a significant correlation with KB220Z treatment compliance, compared to participants with the normal DA $\mathrm{D}_{2}$ receptors. ${ }^{100}$ An attenuation of craving and relapse prevention, has been shown in double-blind, controlled studies, as well as other research. ${ }^{101-104}$ Indeed, the compensatory overexpression of DRD2 receptors reduces alcohol and cocaine self-administration in in DRD2-deficient or drug preferring rodents. ${ }^{105-107}$

The current research literature supports the need for new approaches to treating RDS. Current therapeutic approaches have not addressed the reduced brain connectivity patterns often observed in individuals with SUD. Existing approaches have had only modest success in treating substance dependence and in preventing relapse. $^{108}$ We hypothesized that high-resolution fMRI would show that KB220Z increases resting-state functional connectivity (rsFC, the correlation of activation between brain areas) and enhances connectivity between the cognitive and reward areas of the brain. ${ }^{109}$ In the Febo et $\mathrm{al}^{109}$ placebo-controlled study, the authors used fMRI and a new state of the art, annotated and segmented rat brain atlas to test the network-level actions of a novel complex mixture of KB220Z. As expected, KB220Z, a dopaminergic agonist, produced enhanced resting functional connectivity and volume recruitment (increase in the volume of brain areas affected by a treatment) between cognitive and reward centers of the rodent brain. These changes in the functional organization of the rodent brain, caused by KB220Z are relevant to the KB220Z-induced reduction of ethanol drinking, in rodents, observed by Solanki et al. ${ }^{105}$

\section{mRNA Profiling}

Many neural pathways and drugs interact to affect mRNA's expression of enzymes that produce neurotransmitters, consequent neurotransmission, and the neuronal receptors responsible for feelings of well-being in animals and humans. ${ }^{110}$ Convergent input of the indirect striatopallidal and the direct striatonigral pathways, to the basal ganglia, and the dopaminergic modulation of these pathways, are very important in reward and aversion learning and substance dependence. ${ }^{111,112}$

To understand the role of the basal ganglia in processing information from these two pathways, Hikida et al ${ }^{113}$ developed a selective, reversible technique for blocking the activity of each pathway. Their results indicated that the effect of dopamine mediated psychostimulants required the coordinated modulation of the striatonigral and striatopallidal pathways. The direct striatonigral pathway was predominant in reward learning and cocaine sensitization, whereas the indirect, striatopallidal pathway was involved in aversive learning. These two pathways have different functional roles, the striatonigral pathway discriminating stimuli associated with reward and nonreward, and the striatopallidal pathway supporting memory for aversive stimuli.

"What is the role of drugs of abuse on mRNA in these pathways?" We have carefully explored this concept especially since it has an important function in helping to determine treatment outcomes pre- and post-treatment. This has culminated in the development of the a map yielding for the first time a comprehensive test involving multiple mRNA expressions utilizing array analysis to detect the type of expression (up or down) dependent upon the drug in question for a particular subject (Supplement, Table S2).

Therefore, utilizing GARS, the mRNA outcome test for each patient follows the GARS test result as they enter the treatment facility or primary care program followed by a number of weekly retests to pinpoint any formidable changes in mRNA expression. 
An early example of mRNA gene expression and SUD was the Noble et $\mathrm{al}^{114}$ discovery that the brains of alcoholic and non-alcoholic subjects differed in the binding affinity and number of binding sites of the dopamine D2 receptor in the caudate nucleus. The binding affinity of the D2 receptor and the number of D2 receptor binding sites were lower in alcoholics compared to non-alcoholics. Furthermore, subjects with the A1 allele who also had alcoholism showed significantly reduced dopamine D2 receptor sites. The number of these sites was progressively reduced as the involvement of the $\mathrm{A} 1$ allele increased from the A2/A2, to A2/A1 to A1/A1 genotypes. Subjects with the A2/A2 genotype had the highest number of dopamine D2 receptor sites whereas subjects with the A1/A1 genotype had the lowest number of D2 binding sites. In fact, the A1/A1 subjects demonstrated decreased protein expression in association with a $30-40 \%$ reduction in dopamine D2 receptors. The differential expression of dopamine D2 receptors as a function of the polymorphic pattern of the dopamine D2 receptor gene supports the involvement of the dopamine system in vulnerability to a subtype of severe alcoholism.

The Noble et al ${ }^{114}$ study is an example of the effect of the dopamine receptor gene alleles on Reward Deficiency Syndrome. There are ten genes and eleven alleles ${ }^{21}$ that influence RDS behaviors. Each allele changes the expression of RNA transcription with the effect of decreasing protein synthesis. In Noble et $\mathrm{al},{ }^{114}$ the $\mathrm{A} 1 / \mathrm{A} 1$ allele showed reduced protein expression in association with reduced dopamine D2 receptors in the caudate nucleus.

\section{Overcoming "Genomic Disparity" with Precision Medicine}

Given the advent of precision medicine, the authors contend that the term "race", as a definition of the biology of individuals and populations is obsolete and should be dropped from current usage. We suggest the use of genome-based terminology in the definition of individuals and/or populations, associated with their country/continent of origin (eg, African-Americans, Euro, Anglo or Caucasian-Americans, Mexican-Americans, etc.). Current human populations exhibit continuous genetic variations (polymorphisms) that defy clear division into race/racial groups or subgroups. The authors propose associating biological and/or clinical phenotypes with the genetic variation that underlies biological pathways, processes and/or mechanisms, rather than using "race" as a biological group or subgroup in human genome research. This is crucially important in this time of precision medicine when the power of research on genetic variation, to reveal the biological bases of clinical phenotypes, is reduced by outmoded descriptions of populations as "race(s)". The latter point is especially relevant for African-Americans, a population that displays wide genetic variation reflective of its more recent population history in America. ${ }^{115}$

In this article, we have selected the term "ethnicity" instead of race. However, we are cognizant that "race" is so entrenched in the American mindset as a surrogate for biology, that it has been almost impossible to "change the mindset" of the American people who are deeply rooted in the appearance of "race" as a biological construct.

\section{Prevalence of the DRD2 Taq AI Allele as a Function of Ethnicity: An Example of Variation}

Barr and Kidd ${ }^{35}$ have raised an important issue with early research on the frequency of the DRD2 Taq1 allele in various ethnic groups. Their concern is that variations in this allele in Caucasians have not effectively reflected stratification by ethnic groups, and, this has produced heterogeneity in samples of participants included in research studies. Barr and Kidd' ${ }^{35}$ views are supported by studies of German, American Indian and Finish alcoholics. However, deeper analysis indicates that proper categorization of subjects in terms of severity of alcoholism was not completely addressed. The presence of the DRD2 A1 allele, in and of itself, may not necessarily produce alcoholism. One must also consider environmental factors, including the epigenetic effect of the social environment on gene expression. In this regard, Goldman et $\mathrm{al}^{116}$ failed to find a correlation between a high frequency of the A1 allele of the DRD2 gene in Cheyenne Indians, and alcoholism and drug abuse, using subjective interviewing. This result is understandable, given that Levy and Kunitz ${ }^{117}$ found a $60 \%$ rate of abstention among Native Americans who had taken an oath not to use drugs, compared to $25 \%$ in the general population. In contrast, Ishiguro et $\mathrm{al}^{118}$ reported that severe alcoholics, compared to less severe alcoholics had a significantly higher frequency of the DRD2 A1 allele. These researchers also found that all of the alcoholics with the A1/A1 genotype were in the severe alcoholism category. ${ }^{119}$

Barr and Kidd $^{35}$ highlighted ethnic variation in the frequency of the DRD2 A1 allele with a gene map 
demonstrating that Yemeni Jews, known to have low rates of alcoholism, had an A1 allele frequency of 0.09 . American Cheyenne Indians, in contrast, known in most research to have high rates of alcoholism, had an A1 allele frequency of 0.75 . It is important to note that the DRD2 A1 allele frequency in African Pygmies is 0.25, compared to $0.5-0.75$ in Colombian, Mayan, and other ethnicities in the Americas. The allelic frequency of the DRD2 A1 allele in African Americans likely varies due to admixture effects, and an interracial impact on the frequency of the DRD2 A1 allele. Albeit social and economic disparities can influence the epigenetic landscape and interact with gene variations to influence RDS behaviors, it has not been shown that African-Americans experience a higher risk for RDS behaviors compared to Euro-Americans. ${ }^{7,120,121}$ The authors are mindful of the fact that human behavior reflects a complex interaction between genetic, epigenetic mechanisms and the powerful influences of the social environment.

The DRD2 Taq A1 or B1 are good examples of how frequency across ethnicity must be addressed in future association studies. Specifically, O'Hara et al ${ }^{121}$ clearly provided pervasive evidence from 616 substance abusing and control participants underscoring the differences between A1 restriction fragment length polymorphism (RFLP) frequencies for black and white Americans. The data revealed the nearly exclusive occurrence of the A3 RFLP in African-Americans as well as a low frequency of rare A4 and B3 RFLP's. For African-Americans, neither the A1 nor the B1 RFLP's demonstrated a correlation with substance abuse, whereas Caucasian-Americans had significant correlations with abuse of multiple substances. As a proportion of the maximum potential disequilibrium, Caucasian-Americans and African-Americans display a strong disequilibrium of linkage between these loci. However, African-American individuals display many more A1/B2 chromosomes. The authors warn that ethnic/ racial variations in Taq1 RFLP haplotypes emphasize the importance of caution in understanding allelic correlations when careful matching for ethnicity has not been accomplished. Abijo et $\mathrm{al}^{7}$ point to novel and/or unique gene variations in African-Americans and to the disparities in research specifically to understand the biology of SUD in this group. Cognizant that genetic risk polymorphisms can influence drug susceptibility and metabolism differently, they also proposed that ethnicity-informed genetics is necessary to provide real precision-guided therapeutics.
Finally, generally speaking, dopamine D2 receptor gene alleles are notable for their polymorphic $\mathrm{A}$ and B Taq1 locations, about $10 \mathrm{~kb} 3^{\prime}$ to the final exon and bordering the second exon, respectively. Some studies, but not all, have found that these alleles are more common in heavy substance users, compared to controls. A significant association has been revealed by meta-analyses of combined data from available studies. ${ }^{121-123}$

\section{Precision Medicine}

Based on evidence from, Ettienne et al ${ }^{123,124}$ utilization of pharmacogenetic testing has paved the way for "precision" dosing of buprenorphine to a highly substance dependent African-American population in Washington DC. Buprenorphine, a partial $\mu$ agonist, is considered by many as a safe and effective Opiate Substitution Therapy (OST) for opioid dependence. However, limitations on dosing differ greatly among the states and among insurance plans, including state Medicaid programs and federal Medicare part D pharmaceutical benefits plans. These limitations are often attributed to "federal guidelines" when they are often covert costs and/or supposed diversion reduction schemes. ${ }^{125}$ For example, the statewide Massachusettsforced decrease of buprenorphine to $16 \mathrm{mg}$ produced limited savings, an uncertain reduction in diversion and increased relapse in patients who were previously stable. This dosing discrepancy was reviewed by Accurso and Rastegar $^{126}$ who found that; (1) the optimal dose of buprenorphine, administered in office settings is not known; (2) The imposition of a decrease in buprenorphine doses was correlated with increases in abnormal drug tests; and (3) Control group patients with higher buprenorphine doses showed greater treatment retention. Finally, the data suggested that some patients benefitted from doses above 16 mgs and doses below $16 \mathrm{mgs}$ were harmful. In preliminary studies, the National Human Genome Center (NHGC) at Howard University and Howard University College of Pharmacy applied pharmacogenetic testing of buprenorphine (+Naloxone) metabolism in a study population consisting of $98 \%$ African-Americans, specifically using CYP3A4, the major metabolizing enzyme for Buprenorphine. Genotyping 144 patients revealed a wide polymorphic variation. Eighty-five percent of the population had the extended metabolic $1 * \mathrm{~B}$ allele. They found that $43 \%$ had the $* 1 / * 1 \mathrm{~B}$; and $42 \%$ carried the $* 1 \mathrm{~B} / * 1 \mathrm{~B}$ homozygote. $^{123,124}$

Compared to over approximately 9000 samples, the same laboratory employed by Ettienne-Chapman's group 
found a mixed population to carry $17 \% * 1 / * 1 \mathrm{~B}$ and $9 \%$ $* 1 \mathrm{~B} / * 1 \mathrm{~B}$ or only $26 \%$ carried the extended $* 1 \mathrm{~B}$ metabolizer. This acknowledges that for Caucasians the promoter variant CYP3A4*1B $(-392 \mathrm{~A}>\mathrm{G})$, has an allelic frequency of $2.9 \%$, but for African-Americans, the allelic frequency of the promoter variant is $35-67 \%{ }^{121}$ Therefore, the take home message, based on genetics alone, is that these patients are unlikely to experience adverse effects from increased buprenorphine dosing (ie, greater than $16 \mathrm{mg}$ per day), because they metabolize buprenorphine rapidly. In their clinic, they have seen intermediate metabolizers of Buprenorphine tolerate up to $24 \mathrm{mg}$ daily. While they are cognizant that prescribed multiple pharmaceuticals are taken besides buprenorphine in their patient population, and possible drug-gene interactions and epigenetic impacts can occur on chromosomes, Chapman's group have proposed routine pharmacogenetic profiling. This will at least determine more personalized or precision pharmacologically based buprenorphine dosing that will reduce relapse by increasing drug efficacy, thereby reducing diversion and poly-pharmacy adverse effects. Finally, the Ettienne et al $^{123}$ data suggest that higher doses of buprenorphine will be needed in some subpopulations to decrease treatment failures; and (1) are unlikely due to widespread patient diversion of medication; (2) should not be limited by the cost of medication; and (3) should be guided by the patients' genetic/epigenetic variations and needs regarding metabolism of drugs.

However, there is the opportunity to also evoke pharmacogenomic induced precision medicine as well. ${ }^{126,127}$ DNA Customization of nutraceutical products, which "nourish" the potential for optimized gene expression, can be achieved. The pro-dopamine regulator, $\mathrm{KB} 220 \mathrm{Z}$ is an example. Continuing discoveries have been an important catalyst for the evolution, expansion, and scientific recognition of the significance of nutrigenomics and its contributions to human health. Truly, "Gene Guided Precision Nutrition" variations of KB220Z, which are mixtures of amino acids, herbals and trace metals, are pioneering innovations and standard-bearers for dose adjusted DNA customization. Research results from Blum et al, ${ }^{10}$ regarding genetic shaping of cravings and pleasureseeking was the first step in our understanding of how genetics influences our actions and our physical and mental health. In addition, the technology represented by KB220Z and its variants that seeks to modify gene expression to control or eliminate cravings, is a cornerstone of the practical application of nutrigenomics. Ongoing research findings have catalyzed the evolution and scientific recognition of nutrigenomics and its important contribution to human health.

The Genetic Addiction Risk Severity (GARS) test, which has the capability of predicting the severity of alcohol and drug use, as well as non-substance dependent behavior, is part of an important, new field of scientific investigation. Neuro-nutrigenomics has the potential for improving human well-being. Notwithstanding the need for more research, neuro-neutrogenomics may provide clinical benefit for addiction medicine. There are, however, 3 studies published on customization of KB220Z a neuroneutrigenomic compound, to combat obesity based on targeting DNA polymorphisms. Through 15 variant formulas, Blum's team ${ }^{100,128,129}$ used polymorphic targets of reward genes (Dopaminergic, Opioidergic, Serotonergic and GABAergic) to customize KB220Z a neuro-neutrigenomic compound [Neuroadaptogen amino-acid therapy (NAAT)] with specific algorithms. A small sample of obese subjects in the Netherlands, selected from a larger group of 1000 , was given KB220Z formulas which were tailored to their personal profile of DNA polymorphisms. The group demonstrated a substantial drop in Body Mass Index (BMI) and weight (lb.). ${ }^{100}$

We are proposing a generalized approach called "Precision Behavioral Management". This approach consists of 1) Early pre-disposition assessment and determination (even in children) with the GARS, a 10 candidate polymorphic gene panel shown to predict ASI-alcohol and drug severity; 2) validated RDS questionnaire; 3) Utilization of the Comprehensive Analysis of Reported Drugs (CARD ${ }^{\mathrm{TM}}$ ) during actual treatment to determine compliance with prescribed medications and abstinence from non-prescribed and illicit drugs of abuse, and importantly; 4) Utilization of a "Pro-dopamine regulator (KB220)" (via IV and oral [KB220Z] delivery systems) to prevent relapse by induction of dopamine homeostasis, and; 5) Utilization of targeted DNA polymorphic reward genes to direct $\mathrm{mRNA}$ genetic expression profiling during the treatment process.

Incorporation of these events can be applied not only to, for example, the African-American community, but for all victims of RDS as a demonstration of a paradigm shift that uniquely provides a novel putative "standard of care" based on DNA guided precision nutrigenomic therapy to induce "dopamine homeostasis." (see Figure 1). Indeed, some of the work implementing the Behavioral Management System in AfricanAmericans has already begun via a grant awarded to GondréLewis and Blum by the National Institutes of Health. 


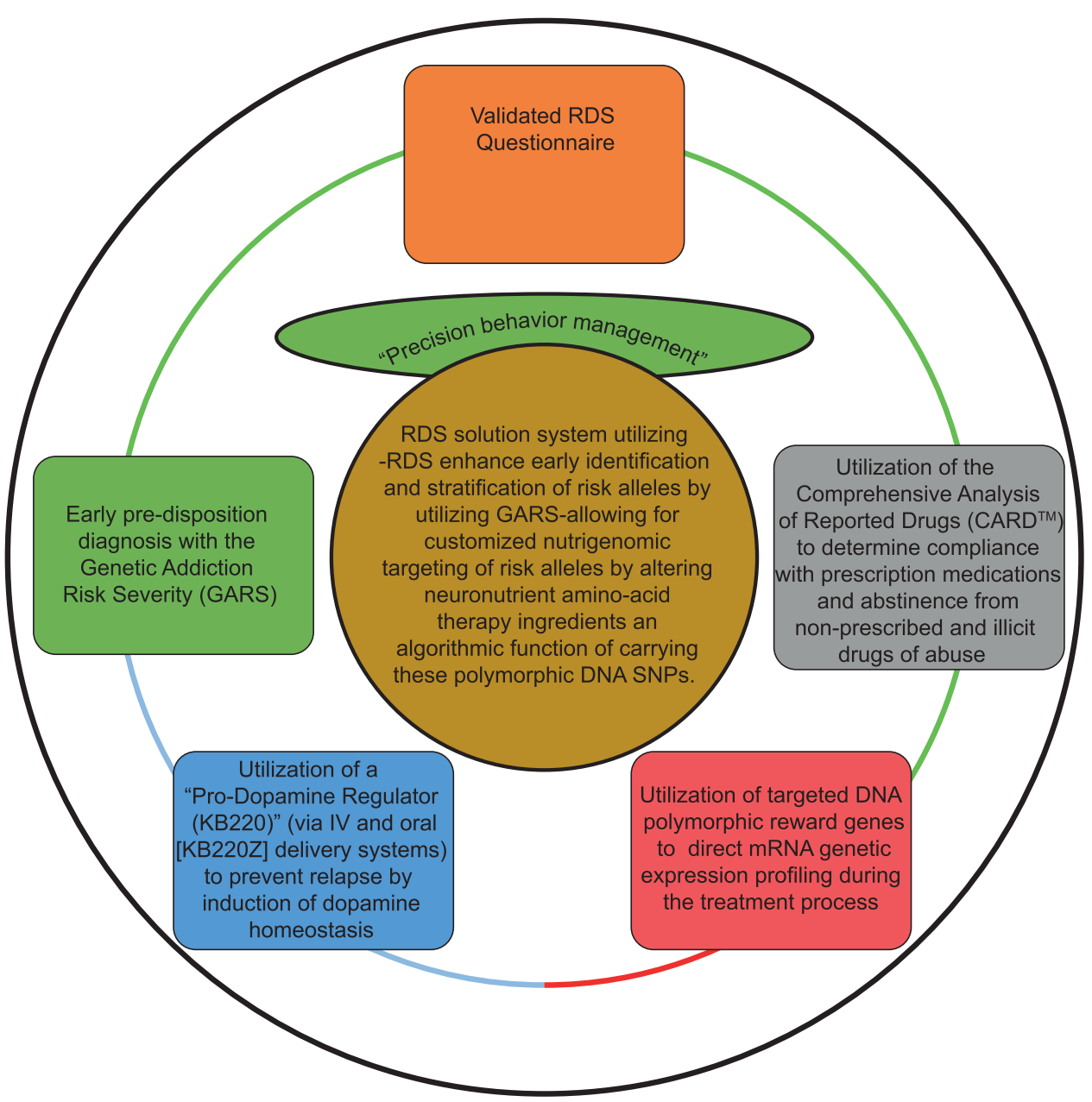

Figure I Reward Deficiency Syndrome Solution ${ }^{\mathrm{TM}}$ for identification of risk alleles with the Genetic Addiction Risk Severity (GARS). The figure describes the Reward Deficiency Syndrome Solution System ${ }^{\mathrm{TM}}$ that proposes using the Genetic Addiction Risk Severity (GARS) to identify and stratify risk alleles for targeting by individualized nutrigenomic preparations. Our approach called "Precision Behavioral Management" consists of; I) Early pre-disposition assessment and determination (even in children) with the Genetic Addiction Risk Severity (GARS), a 10 candidate polymorphic gene panel shown to predict ASI-alcohol and drug severity; 2) validated RDS questionnaire; 3) Utilization of the Comprehensive Analysis of Reported Drugs (CARD ${ }^{\text {TM}}$ ) during actual treatment to determine compliance with prescribed medications and abstinence from non-prescribed and illicit drugs of abuse, and importantly; 4) Utilization of a "Pro-Dopamine Regulator (KB220)" (via IV and oral [KB220Z] delivery systems) to prevent relapse by induction of dopamine homeostasis, and; 5) Utilization of targeted DNA polymorphic reward genes to direct mRNA genetic expression profiling during the treatment process.

\section{Conclusion}

Blum et $\mathrm{al}^{99}$ reported in research with abstinent heroin dependent individuals that a variant of KB220Z increased resting state functional connectivity and enhanced activation in a network including the medial frontal gyrus, dorsal anterior cingulate and posterior cingulate gyri, nucleus accumbens, occipital cortices and the cerebellum. Febo et al, using rodents, demonstrated that KB220Z, compared to placebo, activated regions of interest including the left nucleus accumbens, anterior thalamic nuclei, cingulate gyrus, hippocampus, prelimbic and infra-limbic locations. ${ }^{109}$ This effect of KB220Z reveals increased functional connectivity, restoration of healthy aerobic metabolism evidenced by increased blood oxygen level dependent signaling/functioning (BOLD), increased brain volume recruitment and increased function of dopamine in the brain's reward system, even as a clear reduction in motivation for drug-seeking activity was evident, in ethanol preferring rodents. ${ }^{105}$ This strong, specific reaction is clearly clinically relevant.

After considerable research the authors offer a Reward Deficiency Syndrome Solution System ${ }^{\mathrm{TM}}$ that proposes the use of GARS for early identification and stratification of risk alleles to develop individualized neuronutrient amino-acid therapy, created to match the individual's profile of DNA SNP's. With additional research, this unique approach could produce the first nutrigenomic solution for 
addiction, pain and RDS behaviors and introduce an era of genomic addiction medicine.

Finally, we are cognizant of the work of others ${ }^{130}$ who found that compared to Native Americans, AfricanAmericans and Asians have a lower prevalence of alcohol abuse and dependence. Furthermore, relative to EuropeanAmericans, African-Americans have lower consumption across all ages, a later onset of drinking, but greater health problems associated with alcohol. This is where the social determinants of health become important. Even though African Americans consume less alcohol, they face greater health risks, possibly due to co-occurring medical conditions. When the reward circuitry is inadequately funded with nutritional resources to optimize gene expression, as is prevalent in today's modern agribusiness, food processing and fast food systems environment, those individuals can participate in potentially unhealthy and even dangerous excessive reward-seeking or self-medicating behaviors, such as substance abuse, to achieve reward satisfaction.

In terms of genetic studies, we must be careful to include various ethnic groups when trying to determine candidate genes as well as utilizing Genome Wide Association Studies as antecedents to RDS behaviors. Two possible hypotheses may account for the correlation of any allele (DRD2 A1,B1) with RDS behavior: (1) linkage disequilibrium of A1 and B1 RFLP's with an allelic determinant that affects behavior; (2) the individuals affected disproportionately come from populations stratified by a factor such as ethnicity that is associated with greater A1 and B1 RFLP frequencies.

In this regard, we are proposing the paradigmatic shift called "Reward Deficiency Syndrome Solution System" and its requirement to encourage more research in this fundamental area of investigation. ${ }^{131,132}$

By definition, all inventions are outside the realm of conventional thinking. Inventions generally go through 3 stages towards acceptance: 1 . Outright criticism and rejection (as it threatens to change the way things are or are done); 2. Virulent cynicism and opposition; 3. Gradual and popular acceptance as self-evident. The invention of the KB220Z and the GARS technology many decades after the discovery of the genetic link to severe alcoholism, represents another bold disruptive technological breakthrough by the same scientist that made the previous discovery and one of our coauthors (KB). These technologies represent unprecedented advancements in the nutrigenomics of neuroscience; achieving dopamine homeostasis and a promising ability to restore a life characterized by greater self-control, greater stress tolerance, improved mental sharpness and cognition, better decisionmaking capabilities, and overall mood improvement and a greater sense of happiness. We have gone through the first two stages and are in the $3^{\text {rd }}$ and final stage of acceptance. We encourage clinicians to step outside the "box of conventional dogma"; critically review the more than 40 clinical studies on this technology; and begin adopting its use for clinical applications by physicians and treatment centers alike, especially for those ethnicities that evidence suggest have a higher risk of indulging in life threatening RDS behavioral octopus. $^{7,41,131-134}$

Finally, it is of interest that most recently, Levey et al ${ }^{135}$ reported on a transcriptome-wide association study analyses and revealed significant associations with expression of NEGR1 in the hypothalamus and DRD2 in the nucleus accumbens, among others linked to approximately 1.2 million veterans and 59,000 African-Americans, with major depression. This is particularly important because the original work by Blum, Noble \& Sheridan in $1990^{10}$ also suggested that the DRD2 A1 allele was not specific for alcoholism but was linked to a non-specific reward phenotype like depression.

\section{Acknowledgments}

The authors appreciate the expert edits of Margaret A. Madigan.

\section{Author Contributions}

All authors made a significant contribution to the work reported, whether that is in the conception, study design, execution, analysis and interpretation, or in all these areas; took part in drafting revising or critically reviewing the article; gave final approval of the version to be published; have agreed on the journal to which the article has been submitted; and agree to be accountable for all aspects of the work.

\section{Funding}

$\mathrm{KB}$ and MGL are NIH recipients of R41 MD012318/MD/ NIMHD NIH HHS/United States.

\section{Disclosure}

$\mathrm{KB}$ is the inventor and has an equitable interest and holder of related USA patents issued and pending and foreign patents issued in Europe for genetic testing. $\mathrm{KB}$ and $\mathrm{RB}$ are executives of Geneus Health, LLC and KB owns equity in $\mathrm{GH}$ and iVitalize, Inc. KB, through Geneus Health LLC, 
has licensed KB220 technology to Victory Nutrition International (VNI). KB acts as a scientific advisor to VNI. MCGL, DB, EJM and RDB are unpaid members of GH's scientific Board. BWD received a license to market the KB220Z from Synaptamine, LLC. The authors report no other conflicts of interest in this work.

\section{References}

1. SAMHSA. Available from: SAMHSA.gov/data/report/results2013-national-survey-drug-use-and-health-detailed-tables. Accessed November 24, 2021

2. National Institutes on Drug Abuse, Substance Abuse and Mental Health Services Administration. National survey on drug use and health, 2014-2020. Available from: SAMHSA.gov/data/data-wecollect/NSDUH-National-Survey-drug-use-and-health. Accessed November 24, 2021.

3. Hingson R, Heeren T, Winter M, et al. Magnitude of alcoholrelated mortality and morbidity among U.S. college students ages 18-24: changes from 1998-2001. Annu Rev Public Health. 2005;26:2590279. PMID: 15760289. doi:10.1146/annurev. publhealth.26.021304.144652

4. National Institutes of Health, National Institute of Drug Abuse. Monitoring the future national survey results on drug use, 19752019, volume 1: secondary school students; 2019.

5. Volkow ND. Pandemic worsens opioid crisis: NIDA director; July 2020. Available from: https://drugfree.org/drug-and-alcohol-news /pandemic-worsens-opioid-crisis-NIDA-Director/. Accessed No vember 24, 2021.

6. Davenport S, Weaver A, Caverly M. Economic impact of non-medical opioid use in the United States: annual estimates and projections for 2015 through 2019. Society of Actuaries. Schaumberg, Illinois; 2019. Available from: www.SOA.org. Accessed November 24, 2021.

7. Abijo T, Blum K, Gondré-Lewis MC. Neuropharmacological and neurogenetic correlates of Opioid Use Disorder (OUD) as a function of ethnicity: relevance to precision addiction medicine. Curr Neuropharmacol. 2020;18(7):578-595. doi:10.2174/1570159X17666191118125702

8. Wu X, Hudmon K, Detry M, et al. D2 dopamine receptor gene polymorphisms among African-Americans and Mexican-Americans: a lung cancer case-control study. Cancer Epidemiol Biomarkers Prev. 2000;9(10):1021-1026.

9. Blum K, Chen ALC, Thanos PK, et al. Genetic addiction risk score (GARS) ${ }^{\mathrm{TM}}$, a predictor of vulnerability to opioid dependence. Front Biosci. 2018;10:175-196. doi:10.2741/e816

10. Blum K, Noble EP, Sheridan PJ, et al. Allelic association of human dopamine D2 receptor gene in alcoholism. JAMA. 1990;263 (15):2055-2060. doi:10.1001/jama.1990.03440150063027

11. Noble EP, Blum K, Khalsa ME, et al. Allelic association of the D2 dopamine receptor gene with cocaine dependence [published correction appears in drug alcohol depend 1993 Dec;34(1):83-4]. Drug Alcohol Depend. 1993;33(3):271-285. doi:10.1016/03768716(93)90113-5

12. Camplain R, Camplain C, Trotter R, et al. Racial/ethnic differences in drug and alcohol-related arrest outcomes in a Southwest county from 2009 to 2018. Am J Public Health. 2020;110(S1): S85-S92. doi:10.2105/AJPH.2019.305409

13. Green KM, Doherty EE, Ensminger ME. What's drugs got to do with it? Addict Beh. 2020;110:106539. doi:10.1016/j.addb eh.2020.106539

14. Downs BW, Blum K, Baron D, et al. Death by opioids: are there non-addictive scientific solutions? J Syst Integr Neurosci. 2019;5. doi:10.15761/JSIN.1000211
15. Blum K, Gondré-Lewis MC, Modestino EJ, et al. Understanding the scientific basis of Post-traumatic Stress Disorder (PTSD): precision behavioral management overrides stigmatization. $\mathrm{Mol}$ Neurobiol. 2019;56(11):7836-7850. doi:10.1007/s12035-0191600-8

16. Blum K, Modestino EJ, Neary J, et al. Promoting Precision Addiction Management (PAM) to combat the global opioid crisis. Biomed J Sci Tech Res. 2018;2(2):1-4. doi:10.26717/ BJSTR.2018.02.000738

17. Blum K, Gold M, Modestino EJ, et al. Would induction of dopamine homeostasis via coupling genetic addiction risk score $\left(\right.$ GARS $\left.^{\circledR}\right)$ and pro-dopamine regulation benefit benzodiazepine use disorder (BUD)? J Syst Integr Neurosci. 2018;4. doi:10.15761/JSIN.1000196

18. Blum K, Gondré-Lewis MC, Baron D, et al. Introducing precision addiction management of reward deficiency syndrome, the construct that underpins all addictive behaviors. Front Psychiatry. 2018;9:548. doi:10.3389/fpsyt.2018.00548

19. Blum K, Modestino EJ, Lott L, et al. Introducing "Precision Addiction Management $\left(\mathrm{PAM}^{\circledR}\right)$ " as an adjunctive genetic guided therapy for abusable drugs in America. Open Access J Behav Sci Psychol. 2018;1(2):1-4.

20. Blum K, Modestino EJ, Gondré-Lewis MC, et al. Global opioid epidemic: doomed to fail without genetically based precision addiction medicine $\left(\mathrm{PAM}^{\mathrm{TM}}\right)$ : lessons learned from America. Precis Med. 2017;2(1):17-22.

21. Blum K, Bowirrat A, Baron D, et al. Biotechnical development of genetic addiction risk score (GARS) and selective evidence for inclusion of polymorphic allelic risk in substance use disorder (SUD). J Syst Integr Neurosci. 2019;6. doi:10.15761/JSIN.1000221

22. Fried L, Modestino EJ, Siwicki D, et al. Hypodopaminergia and "Precision Behavioral Management" (PBM): it is a generational family affair. Curr Pharm Biotechnol. 2020;21(6):528-541. doi:10.2174/1389201021666191210112108

23. Kotyuk E, Magi A, Eisinger A, et al. Co-occurrences of substance use and other potentially addictive behaviors: epidemiological results from the psychological and genetic factors of the addictive behaviors (PGA) study. J Behav Addict. 2020;9(2):272-288. doi:10.1556/2006.2020.00033

24. Blum K, Han D, Modestino EJ, et al. A systematic, intensive statistical investigation of data from the comprehensive analysis of reported drugs (CARD) for compliance and illicit opioid abstinence in substance addiction treatment with buprenorphine/naloxone. Subst Use Misuse. 2018;53(2):220-229. doi:10.1080/ 10826084.2017.1400064

25. Blum K, Han D, Femino J, et al. Systematic evaluation of "compliance" to prescribed treatment medications and "abstinence" from psychoactive drug abuse in chemical dependence programs: data from the comprehensive analysis of reported drugs. PLoS One. 2014;9(9):e104275. doi:10.1371/journal.pone.0104275

26. Miller M, Chen AL, Stokes SD, et al. Early intervention of intravenous KB220IV-neuroadaptagen amino-acid therapy (NAAT) improves behavioral outcomes in a residential addiction treatment program: a pilot study. J Psychoactive Drugs. 2012;44 (5):398-409. doi:10.1080/02791072.2012.737727

27. Febo M, Blum K, Badgaiyan RD, et al. Dopamine homeostasis: brain functional connectivity in reward deficiency syndrome. Front Biosci. 2017;22:669-691. doi:10.2741/4509

28. Nikoshkov A, Drakenberg K, Wang X, et al. Opioid neuropeptide genotypes in relation to heroin abuse: dopamine tone contributes to reversed mesolimbic proenkephalin expression. Proc Natl Acad Sci U S A. 2008;105(2):786-791. doi:10.1073/pnas.0710902105

29. Blum K, Hauser M, Fratantonio J, Badgaiyan RD. Molecular genetic testing in pain and addiction: facts, fiction and clinical utility. Addict Genet. 2015;2(1):1-5. doi:10.1515/addge-2015-0001 
30. Chen AL, Chen TJ, Waite RL, et al. Hypothesizing that brain reward circuitry genes are genetic antecedents of pain sensitivity and critical diagnostic and pharmacogenomic treatment targets for chronic pain conditions. Med Hypotheses. 2009;72(1):14-22. doi:10.1016/j.mehy.2008.07.059

31. Jung Y, Montel RA, Shen PH, et al. Assessment of the association of D2 dopamine receptor gene and reported allele frequencies with alcohol use disorders: a systematic review and meta-analysis. JAMA Netw Open. 2019;2(11):e1914940. doi:10.1001/jamanetworko pen.2019.14940

32. Blum K, Chen AL, Oscar-Berman M, et al. Generational association studies of dopaminergic genes in reward deficiency syndrome (RDS) subjects: Selecting appropriate phenotypes for reward dependence behaviors. Int J Environ Res Public Health. 2011;8 (12):4425-4459. doi:10.3390/ijerph8124425o

33. Blum K, Baron D, Lott L, et al. In search of reward deficiency syndrome (RDS)-free controls: the "holy grail" in genetic addiction risk testing. Curr Psychopharmacol. 2020;9(1):7-21. doi:10.2174/2211556008666191111103152

34. Chen TJ, Blum K, Mathews D, et al. Are dopaminergic genes involved in a predisposition to pathological aggression? Hypothesizing the importance of "super normal controls" in psychiatricgenetic research of complex behavioral disorders. Med Hypotheses. 2005;65(4):703-707. doi:10.1016/j.mehy.2005.04.037

35. Barr CL, Kidd KK. Population frequencies of the A1 allele at the dopamine D2 receptor locus. Biol Psychiatry. 1993;34 (4):204-209. doi:10.1016/0006-3223(93)90073-

36. Hill SY, Zezza N, Wipprecht G, et al. Linkage studies of D2 and D4 receptor genes and alcoholism. Am J Med Genet. 1999;88 (6):676-685. doi:10.1002/(sici)1096-8628(19991215)88:6<676:: aid-ajmg $18>3.0 . \mathrm{co} ; 2$-s

37. Ponce G, Jimenez-Arriero MA, Rubio G, et al. The A1 allele of the DRD2 gene (TaqI A polymorphisms) is associated with antisocial personality in a sample of alcohol-dependent patients. Eur Psychiatry. 2003;18(7):356-360. doi:10.1016/j.eurpsy.2003.06.006

38. Blum K, Oscar-Berman M, Badgaiyan RD, et al. Hypothesizing dopaminergic genetic antecedents in schizophrenia and substance seeking behavior. Med Hypotheses. 2014;82(5):606-614. doi:10.1016/j.mehy.2014.02.019

39. Green AI, Zimmet SV, Strous RD, et al. Clozapine for comorbid substance use disorder and schizophrenia: Do patients with schizophrenia have a reward-deficiency syndrome that can be ameliorated by clozapine? Harv Rev Psychiatry. 1999;6(6):287-296. doi:10.3109/10673229909017206

40. van Ree JM, De Wied D. Neuroleptic-like profile of $\gamma$-type endorphins as related to schizophrenia. Trends Pharmacol Sci. 1982;3:358-361. doi:10.1016/0165-6147(82)91183-X

41. Gondré-Lewis MC, Bassey R, Blum K. Pre-clinical models of reward deficiency syndrome: a behavioral octopus. Neurosci Biobehav Rev. 2020;115:164-188. PMID: 32360413; PMCID: PMC7594013. doi:10.1016/j.neubiorev.2020.04.021

42. Li CY, Mao X, Wei L. Genes and (common) pathways underlying drug addiction. PLoS Comput Biol. 2008;4(1):e2. doi:10.1371/ journal.pcbi.0040002

43. Dang LC, Samanez-Larkin GR, Castrellon JJ, et al. Associations between dopamine $\mathrm{D} 2$ receptor availability and BMI depend on age. Neuroimage. $\quad 2016 ; 138: 176-183 . \quad$ doi:10.1016/j.neuroimage.20 16.05.044

44. Fetsko LA, Xu R, Wang Y. Effects of age and dopamine D2L receptor-deficiency on motor and learning functions. Neurobiol Aging. 2005;26(4):521-530. doi:10.1016/j.neurobiolaging.20 04.04 .005

45. Karrer TM, Josef AK, Mata R, et al. Reduced dopamine receptors and transporters but not synthesis capacity in normal aging adults: A meta-analysis. Neurobiol Aging. 2017;57:36-46. doi:10.1016/j. neurobiolaging.2017.05.006
46. Volkow ND, Wang GJ, Fowler JS, et al. Measuring age-related changes in dopamine D2 receptors with 11C-raclopride and 18F-N-methylspiroperidol. Psychiatry Res. 1996;67(1):11-16. doi:10.1016/0925-4927(96)02809-0

47. Cadet JL. Epigenetics of stress, addiction, and resilience: therapeutic implications. Mol Neurobiol. 2016;53(1):545-560. doi:10.1007/s12035-014-9040-y

48. Kreek MJ, Levran O, Reed B, et al. Opiate addiction and cocaine addiction: Underlying molecular neurobiology and genetics. $J$ Clin Invest. 2012;122(10):3387-3393. doi:10.1172/JCI60390

49. Wang SC, Chen $\mathrm{YC}$, Lee $\mathrm{CH}$, et al. Opioid addiction, genetic susceptibility, and medical treatments: a review. Int J Mol Sci. 2019;20(17):4294. doi:10.3390/ijms20174294

50. Le Foll B, Gallo A, Le Strat Y, et al. Genetics of dopamine receptors and drug addiction: A comprehensive review. Behav Pharmacol. 2009;20(1):1-17. doi:10.1097/FBP.0b013e3283242f05

51. De Sa Nogueira D, Merienne K, Befort K. Neuroepigenetics and addictive behaviors: where do we stand? Neurosci Biobehav Rev. 2019;106:58-72. doi:10.1016/j.neubiorev.2018.08.018

52. Duncan JR. Current perspectives on the neurobiology of drug addiction: A focus on genetics and factors regulating gene expression. ISRN Neurol. 2012;2012:972607. doi:10.5402/2012/972607

53. Onaivi ES, Ali SF, Chirwa SS, et al. Ibogaine signals addiction genes and methamphetamine alteration of long-term potentiation. Ann N Y Acad Sci. 2002;965:28-46. doi:10.1111/j.1749-6632.2002. tb04149.x

54. Li ZH, Liu YF, Li KN, et al. Analysis of functional and pathway association of differential co-expressed genes: A case study in drug addiction. J Biomed Inform. 2012;45(1):30-36. doi:10.1016/ j.jbi.2011.08.014

55. Blum K, Madigan MA, Fried L, et al. Coupling Genetic Addiction Risk Score (GARS) and pro dopamine regulation (KB220) to combat substance use disorder (SUD). Glob J Addict Rehabilit Med. 2017;1(2):25-34. doi:10.19080/GJARM.2017.01.55556

56. Krebs EE, Gravely A, Nugent S, et al. Effect of opioid vs nonopioid medications on pain-related function in patients with chronic back pain or hip or knee osteoarthritis pain: The SPACE randomized clinical trial. JAMA. 2018;319(9):872-882. PMID: 29509867; PMCID: PMC5885909. doi:10.1001/jama.2018.0899

57. Blum K, Oscar-Berman M, Blum SH, et al. Can genetic testing coupled with enhanced dopaminergic activation reduce recidivism rates in the workers compensation legacy cases? J Alcohol Drug Depend. 2014;2(3):161. doi:10.4172/2329-6488.1000161

58. Blum K, Jacobs W, Modestino EJ, et al. Insurance companies fighting the peer review empire without any validity: The case for addiction and pain Modalities in the face of an American drug epidemic. SEJ Surg Pain. 2018;1(1):1-11.

59. Blum K, Oscar-Berman M, Dinubile N, et al. Coupling Genetic Addiction Risk Score (GARS) with electrotherapy: fighting iatrogenic opioid dependence. $J$ Addict Res Ther. 2013;4 (163):1000163. doi:10.4172/2155-6105.1000163

60. Chen TJ, Blum K, Payte JT, et al. Narcotic antagonists in drug dependence: Pilot study showing enhancement of compliance with SYN-10, amino-acid precursors and enkephalinase inhibition therapy. Med Hypotheses. 2004;63(3):538-548. doi:10.1016/j. mehy.2004.02.051

61. Blum K, Modestino EJ, Badgaiyan RD, et al. Analysis of evidence for the combination of pro-dopamine regulator (KB220PAM) and naltrexone to prevent opioid use disorder relapse. EC Psychol Psychiatr. 2018;7(8):564-579.

62. Hill E, Han D, Dumouchel P, et al. Long term Suboxone ${ }^{\mathrm{TM}}$ emotional reactivity as measured by automatic detection in speech [published correction appears in PLoS One. 2013;8(8): doi/10.1371/annotation/be0b3a26-c1bc-4d92-98c1-c516acc8dcf2. Barh, Debmalya [added]]. PLoS One. 2013;8(7):e69043. doi:10.1371/journal.pone. 0069043 
63. Foley KF, DeSanty KP, Kast RE. Bupropion: pharmacology and therapeutic applications. Expert Rev Neurother. 2006;6 (9):1249-1265. doi:10.1586/14737175.6.9.1249

64. Cano-Cebrián MJ, Zornoza-Sabina T, Guerri C, et al. Local Acamprosate modulates dopamine release in the rat nucleus accumbens through NMDA receptors: an in vivo microdialysis study. Naunyn Schmiedebergs Arch Pharmacol. 2003;367 (2):119-125. doi:10.1007/s00210-002-0674-3

65. Quintero GC. Role of nucleus accumbens glutamatergic plasticity in drug addiction. Neuropsychiatr Dis Treat. 2013;9:1499-1512. doi:10.2147/NDT.S45963

66. Gueorguieva R, Wu R, Donovan D, et al. Baseline trajectories of drinking moderate Acamprosate and naltrexone effects in the COMBINE study. Alcohol Clin Exp Res. 2011;35(3):523-531. doi:10.1111/j.1530-0277.2010.01369.x

67. Blum K, Chen TJ, Meshkin B, et al. Manipulation of catechol-O-methyl-transferase (COMT) activity to influence the attenuation of substance seeking behavior, a subtype of Reward Deficiency Syndrome (RDS), is dependent upon gene polymorphisms: a hypothesis. Med Hypotheses. 2007;69(5):1054-1060. doi:10.1016/j.mehy.2006.12.062

68. Karkhanis AN, Rose JH, Weiner JL, et al. Early-life social isolation stress increases kappa opioid receptor responsiveness and downregulates the dopamine system. Neuropsychopharmacology. 2016;41 (9):2263-2274. doi:10.1038/npp.2016.21

69. Blum K, Briggs AH, Elston SF, et al. Reduced leucineenkephalin-like immunoreactive substance in hamster basal ganglia after long-term ethanol exposure. Science. 1982;216 (4553):1425-1427. doi:10.1126/science.7089531

70. Volkow ND, Fowler JS, Wang GJ, et al. Imaging dopamine's role in drug abuse and addiction. Neuropharmacology. 2009;56 (Suppl1):3-8. doi:10.1016/j.neuropharm.2008.05.022

71. Volkow ND, Fowler JS, Wang GJ, et al. Dopamine in drug abuse and addiction: results of imaging studies and treatment implications. Arch Neurol. 2007;64(11):1575-1579. doi:10.1001/ archneur.64.11.1575

72. London ED. Human brain imaging links dopaminergic systems to impulsivity. Curr Topics Behav Neurosci. 2020;47:53-71. doi:10.1007/7854_2019_125

73. Bogomolova EV, Rauschenbach IY, Adonyeva NV, et al. Dopamine down-regulates activity of alkaline phosphatase in drosophila: the role of D2-like receptors. $J$ Insect Physiol. 2010;56(9):1155-1159. doi:10.1016/j.jinsphys.2010.03.014

74. Jeziorski M, White FJ. Dopamine agonists at repeated "autoreceptor-selective" doses: Effects upon the sensitivity of A10 dopamine autoreceptors. Synapse. 1989;4(4):267-280. doi:10.1002/ syn. 890040403

75. Burris KD, Pacheco Ma, Filtz TM, et al. Lack of discrimination by agonists for D2 and D3 dopamine receptors. Neuropsychopharmacology. 1995;12(4):335-345. doi:10.1016/ 0893-133X(94)00099-L

76. Luedtke RR, Artymyshyn RP, Monks BR, et al. Comparison of the expression, transcription and genomic organization of D2 dopamine receptors in outbred and inbred strains of rat. Brain Res. 1992;584(1-2):45-54. doi:10.1016/0006-8993(92)90876-b

77. Ivins KJ, Luedtke RR, Artymyshyn RP, et al. Regulation of dopamine D2 receptors in a novel cell line (SUP1). Mol Pharmacol. 1991;39(4):531-539.

78. McGonigle P, Boyson SJ, Reuter S, et al. Effects of chronic treatment with selective and nonselective antagonists on the subtypes of dopamine receptors. Synapse. 1989;3(1):74-82. doi:10.1002/syn.890030111
79. Filtz TM, Artymyshyn RP, Guan W, et al. Paradoxical regulation of dopamine receptors in transfected 293 cells. Mol Pharmacol. 1993;44(2):371-379.

80. Filtz TM, Guan W, Artymyshyn RP, et al. Mechanisms of up-regulation of D2L dopamine receptors by agonists and antagonists in transfected HEK-293 cells. J Pharmacol Exp Ther. 1994;271(3):1574-1582.

81. Burris KD, Fausing SM, Molinoff PB. Regulation of D2 and D3 receptors in transfected cells by agonists and antagonists. $A d v$ Pharmacol. 1998;42:443-446. doi:10.1016/s1054-3589(08) 60783-8

82. Boundy VA, Pacheco MA, Guan W, et al. Agonists and antagonists differentially regulate the high affinity state of the D2L receptor in human embryonic kidney 293 cells. Mol Pharmacol. 1995;48(5):956-964.

83. Blum K, Chen AL, Chen TJ, et al. Activation instead of blocking mesolimbic dopaminergic reward circuitry is a preferred modality in the long term treatment of reward deficiency syndrome (RDS): A commentary. Theor Biol Med Model. 2008;5:24. doi:10.1186/17424682-5-24

84. Hietala J, West C, Syvalahti E, et al. Striatal D2 dopamine receptor binding characteristics in vivo in patients with alcohol dependence. Psychopharmacology. 1994;116:285-290. doi:10.1007/BF02245330

85. Volkow ND, Wang GJ, Fowler JS, et al. Decreases in dopamine receptors but not in dopamine transporters in alcoholics. Alcohol Clin Exp Res. 1996;20:1594-1598. doi:10.1111/j.1530-0277.1996. tb05936.x

86. Feltmann K, Borroto-Escuela DO, Rüegg J, et al. Effects of Long-term alcohol drinking on the dopamine D2 receptor: gene expression and heteroreceptor complexes in the striatum in rats. Alcohol Clin Exp Res. 2018;42(2):338-351. doi:10.1111/acer.13568

87. Gardner EL. Addiction and brain reward and antireward pathways. Adv Psychosom Med. 2011;30:22-60. doi:10.1159/000324065

88. Blum K, Chen TJ, Downs BW, et al. Neurogenetics of dopaminergic receptor supersensitivity in activation of brain reward circuitry and relapse: Proposing "deprivation-amplification relapse therapy” (DART). Postgrad Med. 2009;121(6):176-196. doi:10.3810/pgm.2009.11.2087

89. Blum K, Badgaiyan RD, Braverman ER, et al. Hypothesizing that, a pro-dopamine regulator (KB220Z) should optimize, but not hyper-activate the activity of trace amine-associated receptor 1 (TAAR-1) and induce anti-craving of psychostimulants in the long-term. J Reward Defic Syndr Addict Sci. 2016;2(1):14-21. doi:10.17756/jrdsas.2016-023

90. Kenneth B, Edward MJ, Marjorie GLC, et al. Pro-Dopamine regulator (KB220) a fifty year sojourn to combat reward deficiency syndrome (RDS): evidence based bibliography (Annotated). CPQ Neurol Psychol. 2018;1(2). Available from: https://www.cientperiodique.com/journal/fulltext/CPQNP/1/2/13.

91. Blum K, Thanos PK, Wang GJ, et al. The food and drug addiction epidemic: targeting dopamine homeostasis. Curr Pharm Des. 2018;23(39):6050-6061. doi:10.2174/ 1381612823666170823101713

92. McLaughlin T, Blum K, Steinberg B, et al. Pro-dopamine regulator, KB220Z, attenuates hoarding and shopping behavior in a female, diagnosed with SUD and ADHD. J Behav Addict. 2018;7(1):192-203. doi:10.1556/2006.6.2017.081

93. Blum K, Febo M, Fried L, et al. Pro-dopamine regulator (KB220) to balance brain reward circuitry in reward deficiency syndrome (RDS). J Reward Defic Syndr Addict Sci. 2017;3 (1):3-13. doi:10.17756/jrdsas.2017-034 
94. McLaughlin T, Han D, Nicholson J, et al. Improvement of long-term memory access with a pro-dopamine regulator in an elderly male: are we targeting dopamine tone? J Syst Integr Neurosci. 2017;3(3). doi:10.15761/JSIN.1000165

95. Blum K, Briggs AH, Trachtenberg MC, et al. Enkephalinase inhibition: regulation of ethanol intake in genetically predisposed mice. Alcohol. 1987;4(6):449-456. doi:10.1016/0741-8329(87)90084-X

96. McLaughlin T, Oscar-Berman M, Simpatico T, et al. Hypothesizing repetitive paraphilia behavior of a medication refractive Tourette's syndrome patient having rapid clinical attenuation with KB220Znutrigenomic amino-acid therapy (NAAT). J Behav Addict. 2013;2 (2):117-124. doi:10.1556/JBA.2.2013.2.8

97. McLaughlin T, Blum K, Oscar-Berman M, et al. Putative dopamine agonist (KB220Z) attenuates lucid nightmares in PTSD patients: Role of enhanced brain reward functional connectivity and homeostasis redeeming joy. $J$ Behav Addict. 2015;4 (2):106-115. doi:10.1556/2006.4.2015.008

98. Blum K, Chen TJ, Morse S, et al. Overcoming qEEG abnormalities and reward gene deficits during protracted abstinence in male psychostimulant and polydrug abusers utilizing putative dopamine D2 agonist therapy: part 2. Postgrad Med. 2010;122 (6):214-226. doi:10.3810/pgm.2010.11.2237

99. Blum K, Liu Y, Wang W, et al. rsfMRI effects of KB220ZTM on neural pathways in reward circuitry of abstinent genotyped heroin addicts. Postgrad Med. 2015;127(2):232-241. doi:10.1080/ 00325481.2015.994879

100. Blum K, Chen AL, Chen TJ, et al. LG839: anti-obesity effects and polymorphic gene correlates of reward deficiency syndrome. Adv Ther. 2008;25(9):894-913. doi:10.1007/s12325-008-0093-z

101. Brown RJ, Blum K, Trachtenberg MC. Neurodynamics of relapse prevention: a neuronutrient approach to outpatient DUI offenders. J Psychoactive Drugs. 1990;22(2):173-187. doi:10.1080/ 02791072.1990.10472542

102. Blum K, Trachtenberg MC, Elliott CE, et al. Enkephalinase inhibition and precursor amino acid loading improves inpatient treatment of alcohol and polydrug abusers: double-blind placebo-controlled study of the nutritional adjunct SAAVE. Alcohol. 1988;5(6):481-493. doi:10.1016/0741-8329(88)90087-0

103. Trachtenberg MC, Blum K. Improvement of cocaine-induced neuromodulator deficits by the neuronutrient tropamine. $J$ Psychoactive Drugs. 1988;20(3):315-331. doi:10.1080/ 02791072.1988.10472501

104. Blum K, Chen ALC, Chen TJH, et al. Putative targeting of Dopamine D2 receptor function in Reward Deficiency Syndrome (RDS) by Synaptamine Complex ${ }^{\mathrm{TM}}$ Variant (KB220): clinical trial showing anti-anxiety effects. Gene Ther Mol Bio. 2009; 13:214-230.

105. Solanki N, Abijo T, Galvao C, et al. Administration of a putative pro-dopamine regulator, a neuronutrient, mitigates alcohol intake in alcohol-preferring rats. Behav Brain Res. 2020;385:112563. PMID: 32070691. doi:10.1016/j.bbr.2020.112563

106. Thanos PK, Michaelides M, Umegaki H, et al. D2R DNA transfer into the nucleus accumbens attenuates cocaine self-administration in rats. Synapse. 2008;62(7):481-486. doi:10.1002/syn.20523

107. Thanos PK, Volkow ND, Freimuth P, et al. Overexpression of dopamine D2 receptors reduces alcohol self-administration. $J \quad$ Neurochem. 2001;78(5):1094-1103. doi:10.1046/j.14714159.2001.00492.x

108. Hu Y, Salmeron BJ, Krasnova IN, et al. Compulsive drug use is associated with imbalance of orbitofrontal- and prelimbic-striatal circuits in punishment-resistant individuals. Proc Natl Acad Sci US A. 2019;116(18):9066-9071. doi:10.1073/pnas.1819978116

109. Febo M, Blum K, Badgaiyan RD, et al. Enhanced functional connectivity and volume between cognitive and reward centers of naïve rodent brain produced by pro-dopaminergic agent KB220Z. PLoS One. 2017;12(4):e0174774. doi:10.1371/journal.pone.0174774
110. Tapocik JD, Luu TV, Mayo CL, et al. Neuroplasticity, axonal guidance and micro-RNA genes are associated with morphine self-administration behavior. Addict Biol. 2013;18(3):480-495. doi:10.1111/j.1369-1600.2012.00470.x

111. Bertran-Gonzalez J, Hervé D, Girault JA, et al. What is the degree of segregation between striatonigral and striatopallidal projections? Front Neuroanat. 2010;4:136. doi:10.3389/fnana.2010.00136

112. Hikida T, Yawata S, Yamaguchi T, et al. Pathway-specific modulation of nucleus accumbens in reward and aversive behavior via selective transmitter receptors. Proc Natl Acad Sci USA. 2013;110(1):342-347. doi:10.1073/pnas.1220358110

113. Hikida T, Kimura K, Wada N, et al. Distinct roles of synaptic transmission in direct and indirect striatal pathways to reward and aversive behavior. Neuron. 2010;66(6):896-907. doi:10.1016/j. neuron.2010.05.011

114. Noble EP, Blum K, Ritchie T, et al. Allelic association of the D2 dopamine receptor gene with receptor-binding characteristics in alcoholism. Arch Gen Psychiatry. 1991;48(7):648-654. PMID: 2069496. doi:10.1001/archpsyc.1991.01810310066012

115. Yudell M, Roberts D, DeSalle R, et al. Science and society: taking race out of human genetics. Science. 2016;351(6273):564-565. doi:10.1126/science.aac4951

116. Goldman D, Brown GL, Albaugh B, et al. DRD2 dopamine receptor genotype, linkage disequilibrium, and alcoholism in American Indians and other populations. Alcohol Clin Exp Res. 1993;17(2):199-204. doi:10.1111/j.1530-0277.1993.tb00749.x

117. Levy JE, Kunitz SJ. Indian Drinking: Navajo Practice and AngloAmerican Theories. New York: Wiley; 1974.

118. Ishiguro H, Arinami T, Saito T, et al. Association study between the $-141 \mathrm{C}$ Ins/Del and TaqI A polymorphisms of the dopamine D2 receptor gene and alcoholism. Alcohol Clin Exp Res. 1998;22 (4):845-848.

119. Arinami T, Itokawa M, Komiyama T, et al. Association between severity of alcoholism and the A1 allele of the dopamine D2 receptor gene TaqI A RFLP in Japanese. Biol Psychiatry. 1993;33(2):108-114. doi:10.1016/0006-3223(93)90309-2

120. Berrettini WH, Persico AM. Dopamine D2 receptor gene polymorphisms and vulnerability to substance abuse in African Americans. Biol Psychiatry. 1996;40(2):144-147. doi:10.1016/ 0006-3223(96)00036-4

121. O'Hara BF, Smith SS, Bird G, et al. Dopamine D2 receptor RFLPs, haplotypes and their association with substance use in black and Caucasian research volunteers. Hum Hered. 1993;43 (4):209-218. doi:10.1159/000154133

122. Blum K, Noble EP, Sheridan PJ, et al. Genetic predisposition in alcoholism: association of the D2 dopamine receptor TaqI B1 RFLP with severe alcoholics. Alcohol. 1993;10(1):59-67. doi:10.1016/0741-8329(93)90054-r

123. Ettienne EB, Chapman E, Maneno M, et al. Pharmacogenomicsguided policy in opioid use disorder (OUD) management: an ethnically-diverse case-based approach. Addict Behav Rep. 2017;6:8-14. doi:10.1016/j.abrep.2017.05.001

124. Ettienne EB, Ofoegbu A, Maneno MK, et al. Pharmacogenomics and opioid use disorder: clinical decision support in an African American cohort. J Natl Med Assoc. 2019;111(6):674-681. doi:10.1016/j.jnma.2019.09.006

125. Reuss CV, Kalava A, King KC. Prescription of Controlled Substances: benefits and Risks. In: StatPearls [Internet]. Treasure Island (FL): StatPearls Publishing; 2021. PMID: 30726003.

126. Accurso AJ, Rastegar DA. The effect of a payer-mandated decrease in buprenorphine dose on aberrant drug tests and treatment retention among patients with opioid dependence. J Subst Abuse Treat. 2016;61:74-79. doi:10.1016/j.jsat.2015.09.004

127. Volkow N. Toward precision medicine in addiction treatment. $\mathrm{Am}$ $J$ Addict. 2018;27(1):35-36. doi:10.1111/ajad.12666 
128. Blum K, Chen TJ, Meshkin B, et al. Genotrim, a DNA-customized nutrigenomic product, targets genetic factors of obesity: hypothesizing a dopamine-glucose correlation demonstrating reward deficiency syndrome (RDS). Med Hypotheses. 2007;68(4):844-852. doi:10.1016/j.mehy.2006.08.041

129. Blum K, Chen TJ, Meshkin B, et al. Reward deficiency syndrome in obesity: a preliminary cross-sectional trial with a Genotrim variant. Adv Ther. 2006;23(6):1040-1051. doi:10.1007/BF02850224

130. Delker E, Brown Q, Hasin DS. Alcohol consumption in demographic subpopulations: an epidemiologic overview. Alcohol Res. 2016;38(1):7-15.

131. Downs B, Oscar-Berman M, Waite R, et al. Have we hatched the addiction egg: reward deficiency syndrome solution system ${ }^{\mathrm{TM}}$. J Genet Syndr Gene Ther. 2013;4(136):14318. doi:10.4172/21577412.100013

132. Blum K, Febo M, Fried L, et al. Hypothesizing that neuropharmacological and neuroimaging studies of glutaminergicdopaminergic optimization complex (KB220Z) are associated with "dopamine homeostasis" in reward deficiency syndrome (RDS). Subst Use Misuse. 2017;52(4):535-547. PMID: 2803347. doi:10.1080/10826084.2016.1244551
133. Nurnberger JI, Austin J, Berrettini WH, et al. What should a Psychiatrist know about genetics? Review and recommendations from the residency education committee of the International Society of Psychiatric Genetics. J Clin Psychiatry. 2018;80 (1):17nr12046. doi:10.4088/JCP.17nr12046

134. Chapman EC, Ettiene E, Ofoegbu A, et al. The impact of pharmacogenetic testing on buprenorphine dosing in an African-American population. Second International Conference on Addiction Medicine and Reward Deficiency Syndrome. March 17-19; 2017; Baltimore, MD.

135. Leavey DF, Stein MB, Wendt FR, et al. Bi-ancestral depression GWAS in the Million Veteran Program and meta-analysis in $>1.2$ million individuals highlight new therapeutic directions. Nat Neurosci. 2021;24(7):954-963. doi:10.1038/s41593-021-00860-2

\section{Publish your work in this journal}

Psychology Research and Behavior Management is an international, peer-reviewed, open access journal focusing on the science of psychology and its application in behavior management to develop improved outcomes in the clinical, educational, sports and business arenas. Specific topics covered in the journal include: Neuroscience, memory and decision making; Behavior modification and management; Clinical applications; Business and sports performance management; Social and developmental studies; Animal studies. The manuscript management system is completely online and includes a very quick and fair peer-review system, which is all easy to use. Visit http://www. dovepress.com/testimonials.php to read real quotes from published authors. 